Running head: BABYWEARING A NICU GRADUATE

\author{
WHAT IS THE EXPERIENCE OF BABYWEARING A NICU GRADUATE? \\ A GRADUATE THESIS \\ SUBMITTED TO THE GRADUATE FACULTY \\ in partial fulfillment of the requirements \\ for the degree of \\ MASTERS OF SCIENCE, NURSING \\ by \\ Robyn Reynolds Miller, BSN, RN, CCRN \\ University of Central Oklahoma \\ Edmond, Oklahoma
}

April 23, 2018 


\section{Signature Page for Thesis Defense}

A Thesis Approved for the Master of Science with Major in Nursing

Student: Robyn Reynolds Miller, BSN, RN

Student ID: 20417850

Thesis Title: What is the Experience of Babywearing a NICU Graduate?

This thesis was submitted by Robyn Reynolds Miller to the University of Central Oklahoma Department of Nursing. It was submitted to the persons listed below in partial fulfillment of the requirements for the degree of Master of Science with a Major in Nursing at UCO.

Geana taulace

Leann Laubach, Ph.D., RN

Committee Chairperson
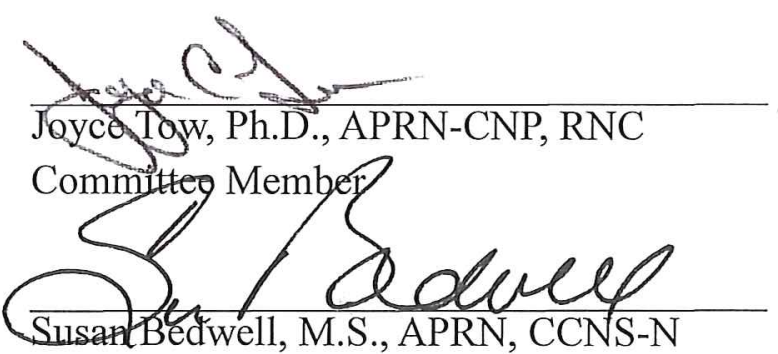

Committee Member

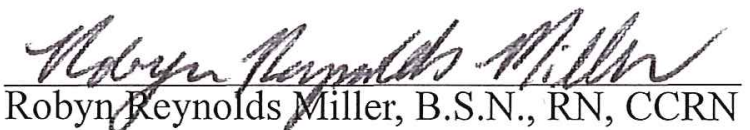

Masters Candidate
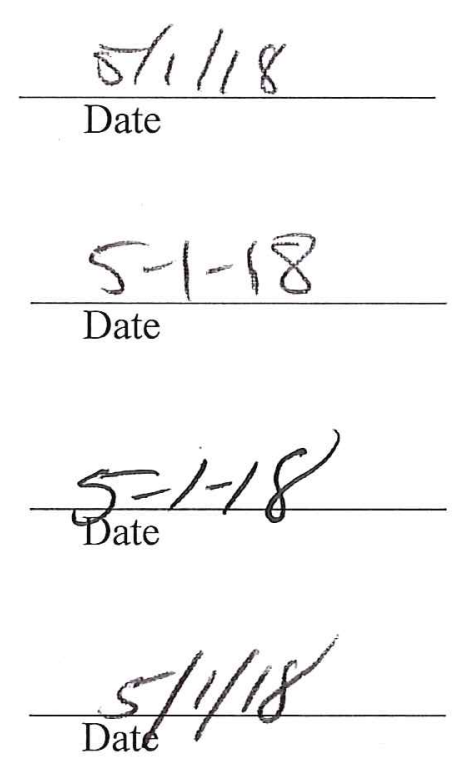


\begin{abstract}
The benefits of skin-to-skin and kangaroo care have been well researched and documented. Despite the large volume of evidence to support various and long-term benefits to both caregivers and children, skin-to-skin care continues to be difficult to practice with eligible caregiver-child dyads. Babywearing may have similar benefits as skin-to-skin care but there is very little scholarly research on babywearing and no research available on babywearing children born prematurely. This study attempts to bring understanding of the effects that babywearing has on caregiver-child dyads after a NICU hospitalization.
\end{abstract}

Six themes were identified in this qualitative phenomenological study. Four themes were similar to themes previously identified in kangaroo and skin-to-skin care research: Bonding, Calmness and Sleep, Decreased Stress and Anxiety, and Parental Empowerment. In addition to these previously described themes, two themes independent to this study were identified: Ease of Work, and Self-care.

There is a paucity of research on the practice of babywearing. This study highlighted the need for further qualitative and quantitative research to support the needs of families caring for children born prematurely. In addition, there is evidence that babywearing could ease the workload for caregivers managing households that include high-needs children, such as premature infants. Another potential research focus should be using babywearing as mitigation for the effects of stress, anxiety, and post-traumatic stress after a NICU discharge for preemie parents.

\title{
Keyword Definitions:
}

Skin-to-skin care - Upright and ventral placement of an infant on a caregiver's chest for up to 24 hours a day. 
Kangaroo care - A method of care for preterm infants that involves three main interventions; skin-to-skin care, exclusive or near-exclusive breastfeeding, and early discharge to home.

Babywearing - The practice of keeping a child close to a caregiver's torso by using a soft baby carrier, usually while the caregiver is active.

Preterm birth - Babies born before 37 completed weeks' gestation.

NICU graduate - Babies discharged after a neonatal intensive care admission. 


\section{Dedication}

This study is dedicated to all the amazing children born too early, the families that journey through the NICU experience with them, and the healthcare professionals that support, educate, and endeavor to heal the tiniest of patients and their families. 


\section{Acknowledgements}

I would like to express sincere appreciation to my committee, Dr. Leann Laubach, Dr. Joyce Tow, and Ms. Susan Bedwell for their unending patience and encouragement during the extended time required to complete this research. To my wonderful family Frankie Jo, Noah, Ashur, and Kale who endured late nights, long hours, and many evenings of Mom not home; many thanks for allowing me to pursue this time-consuming passion of mine and for listening to me debrief myself when problems were encountered. Special thanks to my adult son, Noah, for being the third parent during my graduate education that I said he did not have to be. To Ms. Whitney Bynum and Ms. Ashley Vogel, I am forever grateful to you both for introducing me to the idea and the practice of wearing children with medical needs and equipment. This paper is the result of your ideas and inspirational parenting. Lastly, to all the parents and caregivers of the babies and children involved in this study, thank you so much for the privilege of learning from you. I do not take that privilege lightly and am forever grateful for your trust and partnership in this endeavor. 


\section{Table of Contents}

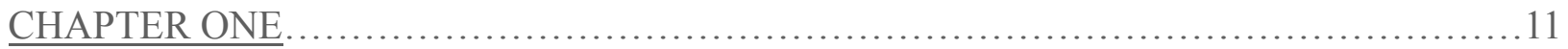

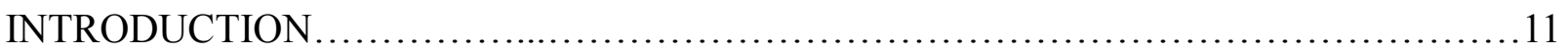

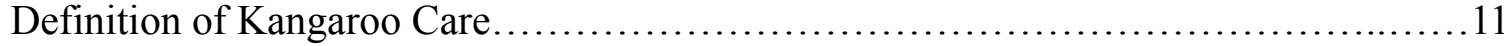

Similarities and Differences between Skin-to-Skin and Babywearing............12

Problem Statement......................................................... 14

FMLA Issues in the NICU.............................................. 14

Theoretical Framework.....................................................15

Maternal Role Attainment.............................................15

Synactive Theory of Newborn Behavioral Organization and Development.....16

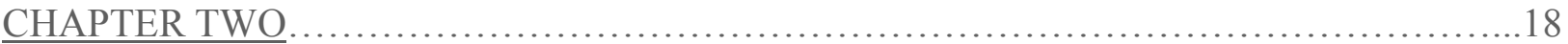

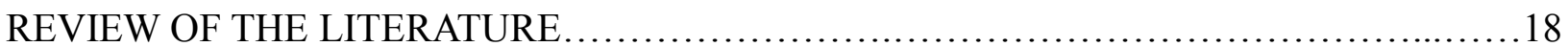

Parental Empowerment.............................................. 18

Parental Readiness for Discharge..........................................19

Fathers in the NICU..................................................20

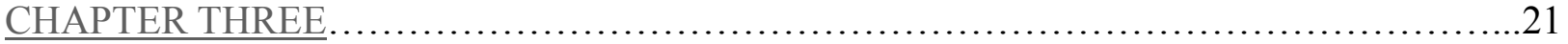

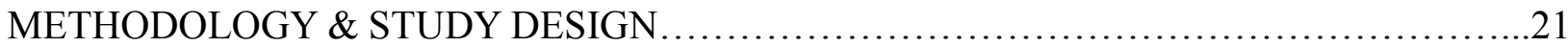

Protection of Human Participants............................................... 22

Population Chosen for this Study...............................................22

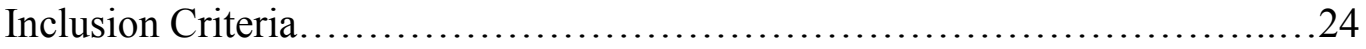

Exclusion Criteria.....................................................24

Potential Risks.............................................................. 24

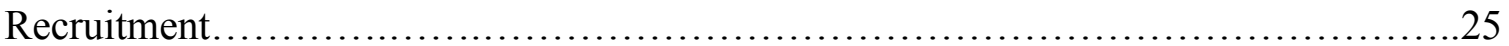




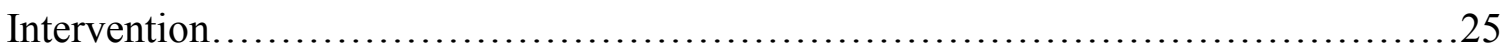

Education...........................................................26

Woven wraps. ...........................................27

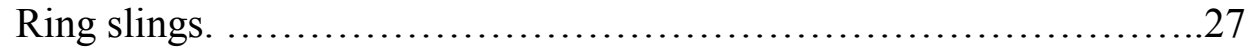

Meh dais..................................................27

Buckle carriers. ..............................................27

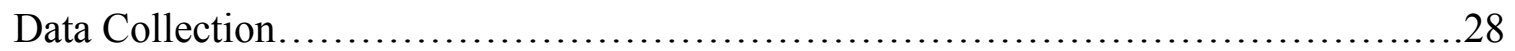

Introduction of Participants.................................................. 30

Data Analysis........................................................... 32

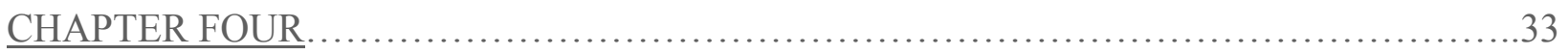

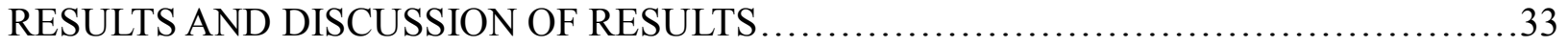

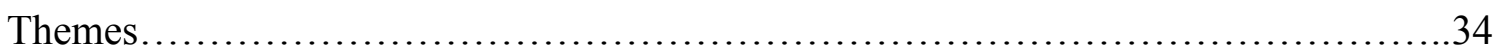

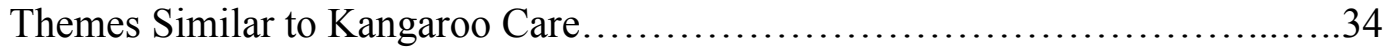

Decreased Anxiety and Stress..................................... 34

Calmness and Sleep.......................................... 35

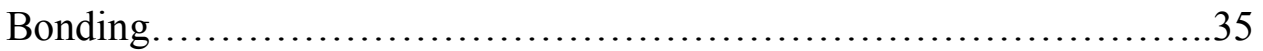

Empowerment..............................................36

Unique Themes.................................................... 36

Ease of Work................................................

Self-care.................................................. 37

Diverse Cases and Minor Themes........................................... 37 


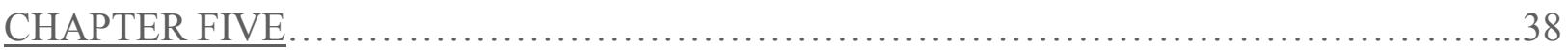

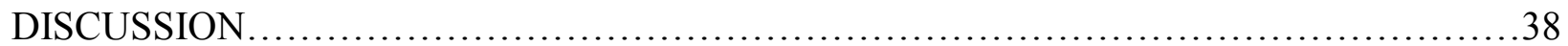

Statement of the Significance of the Findings................................... 38

Contributions to Research.................................................... 39

Implications.......................................................... 39

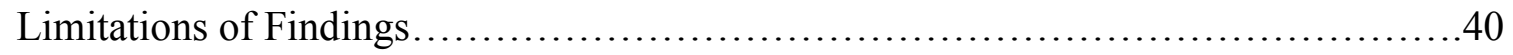

Areas of Future Research..................................................... 41

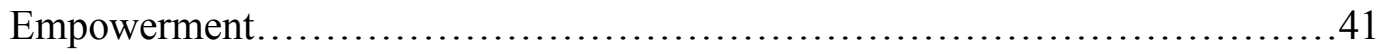

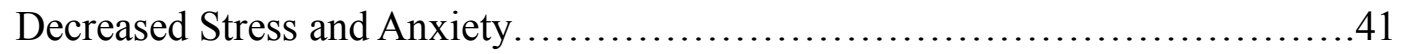

Paternal Roles.....................................................42

Potential to Decrease Risks of Daytime Sleeping..........................42

Potential to Decrease Musculoskeletal Problems...........................43

Potential to Decrease Exposure to Pathogens.................................43

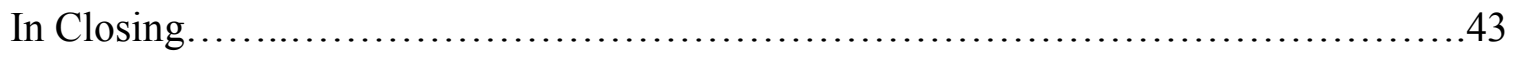

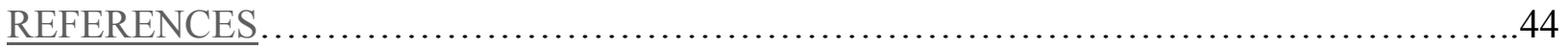

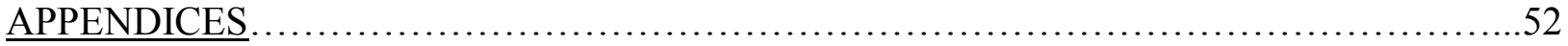

Appendix A. Front cover of WHO publication, Kangaroo Mother Care.................53

Appendix B. WHO guidelines for kangaroo care infant positioning..................54

Appendix C. Permission to reproduce WHO copyrighted material....................55

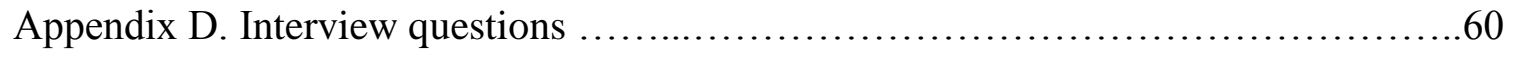

Appendix E. IRB letter of approval..........................................61

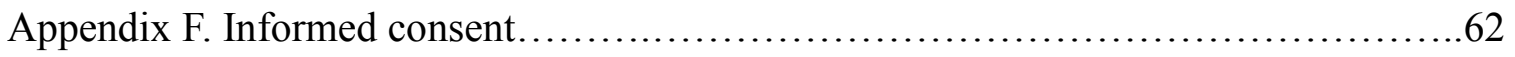

Appendix G. Study contact flyer...........................................66 
Appendix H. Caregiver education.............................................67

Appendix I. Exemplars of Participant Answers to Interview Questions.................70

Appendix J. Coding diagram............................................. 79

\section{List of Tables}

Table 1. Demographics of study participants....................................... 31 


\section{CHAPTER ONE}

\section{Introduction}

Preterm birth is defined by the World Health Organization (WHO) as delivery before 37 completed weeks of gestation (2016). A systematic review of the incidence of preterm birth revealed that causes remain poorly understood (Blencowe et al., 2013). There are 15 million preterm births worldwide with the United States alone responsible for over 517,000 preterm births ranking the U.S. sixth in the world (Blencowe et al., 2013). Despite much attention and intervention, preterm births in the U.S. have continued to rise in the last 20 years and have been consistently high in comparison with other high-income countries (WHO, 2016). While this statistic is concerning, it is also a positive measure of increasing survivability of premature babies as stillbirth rates have consistently dropped. Approximately $90 \%$ of babies born very early ( $<28$ weeks gestation) will survive in the U.S. (WHO, 2016). However, complications due to birth before 37 completed weeks of gestation are the second leading cause of death in children younger than 5 years of age (Blencowe et al., 2013). Moreover, babies born to vulnerable minority groups are at higher risk for preterm birth and infant mortality. Perinatal mortality for black women in America is more than twice the risk for white women. Perinatal mortality has been steadily decreasing since 1995 . The problem is that the gaps between black, Hispanic and white populations have not narrowed (MacDorman \& Gregory, 2015).

\section{Definition of Kangaroo Care}

Kangaroo care $(\mathrm{KC})$ consists of three features: skin-to-skin contact in a ventral and upright position on the caregiver's chest, exclusive or near-exclusive breastfeeding and early discharge from the hospital (WHO, 2003). Thermoregulation is an important goal of kangaroo care for NICU patients. To obtain this, skin-to-skin contact is required as the mother's breasts will regulate heat output to warm a hypothermic infant while preventing overheating (Bergstrom, 
Okong, \& Ransjo-Arvidson, 2007). In the U.S., NICU discharge criteria includes achievement of thermoregulation and kangaroo care is no longer needed.

Dr. Rey and Dr. Martinez in Bogota, Colombia developed the first program of kangaroo care in the NICU in response to increasing mortality of preterm infants and shortage of caregivers and equipment to care for them. They published their results in 1979 but adoption of the intervention has been slow and fraught with complication. The presence of high-level healthcare technology in developed countries serves as a barrier for $\mathrm{KC}$ implementation, as well as low staff to patient ratios, medical instability of premature infants, and difficulties with quantity of caregiver presence (Chan, Labar, Wall, \& Atun, 2016a).

There is no global definition of kangaroo care or agreement on how much time infants should spend in skin-to-skin contact to achieve physiologic or neurodevelopmental benefits (Chan et al., 2016a). In a systematic review of 299 articles focused on KC, $29 \%$ did not include a definition of kangaroo care, and 44\% did not include the number of hours spent in skin-to-skin position. This same systematic review determined that $100 \%$ of the studies that defined kangaroo care included skin-to-skin care as an essential component of KC. Breastfeeding was reported in $35 \%$ of $\mathrm{KC}$ studies, and discharge criteria was used in 5\% (Chan, Valsangkar, Kajeepeta, O'Boundy, \& Wall, 2016b). Kangaroo care evidence is based on meta-analyses of studies that are heterogeneous in their definition of $\mathrm{KC}$ (Chan, et al., 2016b). Because skin-to-skin care is the most widely used intervention of $\mathrm{KC}$, this study focused on caregiver time spent holding infants using a soft baby carrier. 


\section{Similarities and Differences between Skin-to-Skin Care and Babywearing}

Babywearing includes the ventral and upright positioning of a child on a caregiver's chest. While other positions are utilized in typical populations, such as hip/back carries, or forward-facingout, this study limited positioning to kangaroo position as recommended by the World Health Organization (WHO, 2003).

The seminal work of Charpak, Ruiz-Pelaez, and Figueroa (1997) describes their kangaroo care program utilizing early discharge from the typically stressful NICU environment. Dr. Rejean Tessier, kangaroo care researcher explains, “...the kangaroo position induces combinations of sensory modalities: auditory stimulations through the mother's voice, olfactive stimulations by the mother's body proximity, vestibular-kinesthetic stimulations with the infant's location on the adult's chest and carried 24 hours a day for days or weeks, tactile stimulations by permanent skin-to-skin contacts, and visual stimulation... which allows him to see the mother's face and body and the contextual elements as the mother moves in her routine activities." (Tessier, et al., 1998, p. 386). This early description of kangaroo position is more similar to the practice of babywearing than it is to the position of rest and limited mobility practiced at the NICU bedside. The cover of the World Health Organization's 2003 publication, "Kangaroo Mother Care: A Practical Guide" displays a drawing of a man and woman using soft baby carriers underneath their clothing (WHO, 2003) (Appendix A). In order for skin-to-skin contact to be achieved using a baby carrier, both caregiver and infant need to be unclothed above the waist. Babywearing typically involves a layer of clothing between the infant and caregiver. In the U.S., infants must achieve thermoregulation before discharge and thus for this study, the benefits of babywearing are not expected to include thermoregulation. Because kangaroo care research involves skin-to- 
skin care, and babywearing typically involves a layer of clothing between infant and caregiver, it is not known whether babywearing can be an extension of kangaroo care.

\section{Problem Statement: Difficulties Implementing Best Practices in Kangaroo Care}

Though kangaroo care $(\mathrm{KC})$ has long been established as best practice for children and caregivers experiencing NICU stays (Nyqvist et al., 2010) there is great variability in the practice of $\mathrm{KC}$ in NICUs (Ludington-Hoe, 2011). Though the first study of kangaroo care appeared in English in 1990 (Ludington-Hoe, 2011), nurses practicing in the NICU are verbally supportive but ambivalent in the practice of $\mathrm{KC}$ (Kymre, 2014). There is also great variability in an individual's NICU experience. Despite compelling evidence, health, family conditions, staffing, use of medical equipment, parental confidence, and hospital practices may prevent realization of the benefits of KC in the in-patient setting (Feeley, Genest, Niela-Vilen, Charbonnea, \& Axelin, 2016; Ludington-Hoe, 2011). This study seeks a way to mitigate negative effects of NICU stays by promoting babywearing as an extension of kangaroo care after hospital discharge.

Expectations are that babywearing will reveal similar benefits to kangaroo care in improving parental confidence, decreasing stress and anxiety, promoting resilience, and increasing positive outlook toward preterm infants. As a result, facilitation of positive health trajectories is expected for discharged NICU families.

\section{FMLA Issues in the NICU}

The Family and Medical Leave Act entitles covered employees twelve weeks of unpaid, job-protected leave to care for a newborn child (DOL.gov, n.d.). Many families experiencing NICU stays have limited or unfunded medical leave. These families may choose to return to work to postpone using FMLA until after their child is discharged. This creates a problem with parental presence in the NICU. Parental presence is evidence-based to improve patient outcomes 
(Greenfield \& Klawetter, 2016). For families experiencing competing priorities between financial or occupational stability and health, babywearing after a NICU discharge may be a way to mitigate the harms of separation experienced between caregiver and infant in the early neonatal period.

\section{Theoretical Framework}

This study uses two research theories; Ramona Mercer's Maternal Role Attainment and Heidelise Als’ Synactive Theory of Newborn Behavioral Organization and Development.

\section{Maternal Role Attainment}

Ramona Mercer developed the Maternal Role Attainment middle range theory to research the complex process of becoming a mother, with a successful end being competent and confident mothers. This theory was developed to serve as a framework for providing non-traditional mothers with optimal care and nursing support. The process can be broken down into four distinct but overlapping phases.

1. Pregnancy - the mother prepares

2. Initial post-partum - birth through six weeks of age

3. Settling into the new normal

4. Achievement of maternal identity - about four months of age when mother attains competence and confidence and finds joy in motherhood

Mercer posited that when factors disrupt this typical progression such as illness or premature birth, individualized care is needed to mitigate negative effects on the mother and child (Husmillo, 2013). 


\section{Synactive Theory of Newborn Behavioral Organization and Development}

Individualized care is the supporting framework for Heidelise Als' theory of neonatal and preterm neonatal development. The goal of this theory is to mimic the conditions of the womb in the neonatal intensive care unit (NICU) in order to prevent or blunt iatrogenic harm from the hospital environment. The Synactive Theory can help identify signs of stress in the neonate and guide practitioners and family to lessen its effects. There are five major themes in this theory.

1. Motor - posture and muscle tone

2. Autonomic - basic vital functions

3. States of consciousness - sleep, awake, irritability

4. Attention/Interaction - readiness to interact

5. Self-regulatory behaviors - coping mechanisms; grasping, hand to mouth (Als \& McAnulty, 2011)

Als highlights the importance of skin-to-skin contact through embryology. The ectoderm is the outermost germ layer and forms both the skin and nervous system (Spruill, 2015). This helps elucidate why skin-to-skin contact cannot be separated from healthy neurodevelopment in infants.

Als has since developed a program to institute this theoretical framework into nursing practice within the environment of the NICU. The Newborn Individualized Developmental Care and Assessment Program (NIDCAP) was developed to help guide practitioners in reframing the goals of care in the NICU. It is based on four assumptions.

1. Infants will communicate stress in order to obtain help. Decreasing stress optimizes infant development. 
2. Preterm infants belong on the skin of their caregivers as close to 24 hours a day as possible.

3. NICU staff benefits from education on the importance of individualized care, support to withstand the demands of the NICU, and support to manage conflicting feelings related to causing pain in order to benefit neonatal patients.

4. Changing care goals to provide individualized care benefits patients, family members, and NICU staff (Als \& McAnulty, 2011)

In addition to evidence that NIDCAP provides comprehensive care resulting in long-term gains in neurobiological development, there are also significant cost savings for healthcare organizations that implement NIDCAP. Decreased need of early intervention services and education services are a benefit that is difficult to estimate but not difficult to acknowledge (Als \& McAnulty, 2011). The overarching theme of Heidelise Als' work is that babies deserve respectful care in the NICU. 


\section{CHAPTER TWO}

\section{Review of the Literature}

Babywearing is the practice of using a baby carrier to hold a child close to a caregiver's torso. Scholarly research on babywearing is limited. The research that does exist focuses on improved breastfeeding success and the bonds of attachment (Anisfeld, Casper, Nozyce, \& Cunningham, 1990; Pisacane, Continisio, G., Filosa, Tagliamonte, \& Continisio, P., 2012). Because babywearing has strong similarities to skin-to-skin (STS) care, it is theorized to have similar benefits as STS (Reynolds-Miller, 2016). One important difference between STS care and babywearing is that babywearing is typically practiced hands-free and while the caregiver is active. These distinctions provide the opportunity for caregivers of NICU graduates to participate in activities such as self-care, social events, or caring for other children. In allowing caregivers to be active and close to neonates simultaneously, stress may be lessened and caregiver competence and confidence may be higher. Because caregiver stress and anxiety contribute to 30-day readmission rates in NICU graduates (Erdeve et al., 2008) babywearing has the potential to decrease readmission rates due to lower caregiver stress and anxiety. Chan, Labar, Wall, and Atun (2016a) stated that KC uptake improved with wrappers to hold the baby. The difficulty of moving around and completing self-care activities were described as barriers to $\mathrm{KC}$ while baby carriers were described as a support for KC (Blomqvist, Frőlund, Rubertsson, \& Nyqvist, 2013). A systematic review of the barriers and enablers for practice of $\mathrm{KC}$ found that uptake is increased when $\mathrm{KC}$ is practiced at home and when carriers were used to hold the baby (Chan, Labar, Wall, \& Atun, 2016a).

\section{Parental Empowerment}

Families experiencing neonatal intensive care unit (NICU) admissions are at high risk for stress, anxiety, depression, and subsequent symptoms of post-traumatic stress disorder (Kim et 
al., 2015; Sweeney, Rothstein, Ra., Rothstein, Ro., Visintainer, \& Singh, 2016; Tahirkheli, Cherry, Tackett, McCaffree, \& Gillaspy, 2014; Treyvaud, Doyle, Lee, \& Anderson, 2014). NICU stays can undermine parental confidence, in turn, negatively affecting attachment between child and caregivers (Guralnik, 2012). Kangaroo care (KC) can increase parental confidence. A study of fathers participating in STS care revealed enhanced sensitivity and caring behaviors and facilitation of paternal role attainment (Shorey, Hong-Gu, \& Morelius, 2016). The benefits of KC can extend even to adulthood. A longitudinal study found that infants receiving $\mathrm{KC}$ had lower mortality rates and lower socio-deviant conduct resulting in more positive familial relationships twenty years later (Charpak et al., 2017). When infants show neurologic vulnerability for decreased cognitive abilities and IQ at 6 months of age, kangaroo care was a protective intervention. A significant percentage of infants who experienced $\mathrm{KC}$ “caught up" developmentally by age 19-21 years compared to a control group of adults who received traditional incubator care (Tessier, Tarabulsy, Varela, \& Pierce, 2017).

The unique behavioral and cognitive characteristics of preterm children require caregivers to continually adjust parenting behaviors but these same preterm characteristics also create stressors for social parent-child transactions (Guralnick, 2012). If babywearing can be used as a tool to facilitate transition from NICU to home and operate as a type of scaffolding to ease the work of parenting, there is potential for improvement of the behavioral and cognitive sequelae that premature infants experience.

\section{Parental Readiness for Discharge}

According to a qualitative study completed to understand parental readiness for NICU discharge, parents feel more confident they can provide adequate care at home when regimentation of care in the NICU is based on physiologic stability and decreases as the infant 
nears discharge readiness (Burnham, Feeley, \& Sherrard, 2013). When the use of monitors continue until discharge, parents perceive their infants as "not normal" and attempt to replicate NICU processes at home by measuring intake of breastmilk, continuing a feeding schedule, taking regular vital signs, keeping the infant in "isolation", and charting daily cares (Burnham, Feeley, \& Sherrard, 2013). In an early study of kangaroo care, parents who participated in KC saw their children as more "normal" rather than "sick" or "disabled" (Tessier et al., 1998). Improved communication between NICU staff and family can decrease parental stress and increase confidence (Shirazi, Sharif, Rakhshan, Pishva, \& Jahanpour, 2015).

\section{Fathers in the NICU}

Fathers of preterm babies have a different experience of parenthood than fathers of term babies. Fathers of preemies experience higher levels of fear, frustration, depression, anxiety, and psychological stress. Moreover, fathers of preterm infants scored lower on paternal involvement than fathers of term babies (Rimmerman \& Sheran, 2001). A literature review on fathers participating in kangaroo care revealed they felt more in control of unexpected situations, participated more in infant care, had higher oxytocin and lower cortisol levels, felt less stress and anxiety, and exhibited more caring and sensitive behaviors (Blomqvist, Rubertsson, Kylberg, Joreskog, \& Nyqvist, 2012; Shorey, Hong-Gu, \& Morelius, 2016).

Fathers with infants in the NICU experience similar incidence of negative emotional and psychological consequences as mothers but experience less interventions to deal with those consequences than mothers do. To deliver family centered care, interventions to reduce negative sequelae of NICU stays must also involve and target fathers and other caregivers as well as mothers (Kuo, Houtrow, Arango, Kuhlthau, Simmons, \& Neff, 2011). 


\section{CHAPTER THREE}

\section{Methodology and Study Design}

The methodology of this study is phenomenology. Phenomenological research strives to bring understanding regarding the shared experiences of study participants. The researcher sought to understand how babywearing might affect a caregiver's daily experiences and perceptions of their infant after discharge from the NICU by analyzing texts of transcribed interviews.

Dr. H. Als' research has highlighted a particular problem in neonatal care, and that is the disrespect for the neonate as a neurologically complex and vulnerable being, capable of expressing needs and regulating themselves within an environment that includes the physical and emotional presence of a caregiver (Als \& McNulty, 2011). In the neonatal intensive care unit, caregivers may be expected to ignore their baby's elicitors, such as crying and reaching out. Elicitors normally serve to keep the infant safe in the arms of their caregivers. Instead, neonates must wait until medical stability is declared before being cared for and physically touched by their families. This practice is not only dismissive and disrespectful to the neonate, it can also cause emotional harm to caregivers, as evidenced by the high rate of caregiver PTSD following NICU admissions. For these reasons, transcendental phenomenology was chosen in order to focus on the experiences of participants more than the interpretations of the researcher (Creswell \& Poth, 2018). In transcendental phenomenological research, the researcher sifts through interviews looking for significant quotes or statements and combines them into themes in order to bring understanding or convey an essential experience, through the eyes of the experiencer. Delving further, "what" the participants experienced is the textural description and "how" they experienced it is the structural description (Creswell \& Poth, 2018). Interview questions used in this study are grouped as textural or structural descriptions (․ppendix D). 
A qualitative research design was used in this study to help understand the experience of babywearing a child after a NICU hospitalization. Very little scholarly research is available regarding the practice of babywearing. Employing qualitative research to bring more understanding to this experience has a lower potential of introducing bias than a quantitative study, as study participants and not the researchers will verbalize what were the most important themes within their own experiences of babywearing. Once these themes are identified, focused qualitative and quantitative research can bring more understanding about what babywearing can accomplish for families caring for premature children.

\section{Protection of Human Participants}

Institutional Review Board approval was obtained following University of Oklahoma Health Sciences Center requirements (Appendix E). Each participant was informed verbally and in writing that data collection methods would include weekly contacts between the participants and the researcher, and a final interview that would be recorded and transcribed. Participants were informed that the benefits of babywearing are not well researched and that the possible benefits of taking part in the study are the same as babywearing without being in the study.

Baby carriers were provided for each study participant. There were no other incentives. No incentives existed for using a certain type or brand of carrier and study participants were not made aware of any monetary values of carriers.

\section{Population Chosen for this Study}

Participants selected for inclusion were chosen as a convenience sample based on discharge date from the NICU of The Children's Hospital (TCH) of Oklahoma City from November 2, 2017 through December 6, 2017. TCH is a large pediatric hospital located in Oklahoma City, Oklahoma. It houses the only Level 4 NICU in the state and offers 88 beds (OU 
Medicine, 2016). The researcher offered study inclusion to eligible caregiver-child dyads during the discharge education process. Study participants were recruited by flyers posted in NICU patient care areas, information presented after baby care classes attended by caregivers during discharge planning, and word-of-mouth between caregivers of inpatients in the NICU. Informed consent was obtained in the inpatient care areas for fourteen of the study participants, and in the home after discharge for one study participant (Appendix F). A copy of the informed consent and a flyer with contact information was left with families that chose to be included (Appendix G). There was no prior relationship between study participants and the study recruiter. The study recruiter was the main contact for the participants, gathered participant data, and performed the participant interviews at the conclusion of the study period. The researcher introduced herself as a nurse and a graduate student from the University of Central Oklahoma, pursuing a Master's degree in nursing education. Possible biases include that the interviewer has personal interest and an investment of time in babywearing education.

Participants were interviewed until the data reached saturation. Data saturation is a qualitative research process to determine when the researcher has enough information in order to replicate a study and the coding of further information is no longer feasible (Fusch \& Ness, 2015). The number of participants needed to reach saturation was expected to be between eight and fifteen, according to typical phenomenological nursing research (Burns \& Grove, 2011). The participant interviews were conducted around day sixty after discharge from the NICU. Researchers identified the length of time between the discharge date and the interview as a potential for attrition that could hinder the ability to reach data saturation. To avoid this, the maximum of fifteen participants were recruited to account for the possibility of participant 
attrition. Data saturation was reached after six interviews. Eight interviews were completed. Seven study participants were lost through attrition.

\section{Inclusion Criteria}

Caregivers aged 18 and older who had a child (children) cared for in the NICU at The Children's Hospital at OU from November to December of 2017 and expected to transition to their home environment were included in the study.

\section{Exclusion Criteria}

Caregivers taking opioid medications or sedating agents were excluded, to decrease the risk of caregivers having difficulty staying awake while carrying their child using a carrier. Due to lack of funding for interpretation, non-English speaking caregivers were excluded. Babies with known congenital anomalies were excluded from this study. Babies requiring medical equipment after discharge that tether the caregiver were excluded. Caregivers of babies readmitted to an acute care hospital were excluded for the remainder of the study period. Participant 5's infant was found to have a congenital anomaly and was unable to complete the study enrollment process. No other participants were lost due to exclusion criteria.

\section{Potential Risks}

Potential risks of participating in a phenomenological interview include the possibility of stress and anxiety brought on by talking about experiences in the NICU. A majority of parents experience stress and anxiety related to NICU admissions and about $15-25 \%$ experience situational PTSD (Kim et al., 2015; Vanderbilt, Bushley, Young, \& Frank, 2009). Talking about their experiences has the potential to bring negative emotions to the forefront and cause stress and anxiety due to remembering a past traumatic event.

Participants were informed that a potential risk could include stress and anxiety brought 
on by talking about experiences in the NICU prior to discharge. Each participant was advised to seek assistance from their primary care provider in the event they experienced illness in the form of stress and anxiety. In addition, participants received contact information for a free, live support group for parents experiencing antepartum stress or trauma in the metro area, and a peer support group that utilizes volunteers throughout rural Oklahoma including phone and social network connections.

Phenomenology and interviewing in a qualitative manner can be used as a therapeutic technique. Talking about NICU experiences, while anxiety producing, can assist caregivers in establishing perspective and closure. The interview would be terminated if the participant did not wish to continue. No participants verbalized stress or anxiety during the interview.

\section{Recruitment}

Recruitment of study participants occurred from 10 a.m. until 10 p.m. in order to include caregivers who returned to work during their infant's hospitalization. Eleven of the enrolled fifteen and seven of the eight retained participants were recruited in a unit named The Village. This unit encourages rooming in and provides a bed for caregivers. The Village is reserved for families that are looking forward to discharge from the NICU.

Participant 2, who was not retained through the interview process, involved three other caregivers that she met during her boys' hospitalizations. She was observed by the interviewer teaching her NICU nurses about the carrier she was using with her discharged baby while they waited for his twin brother to be discharged.

\section{Intervention}

Participants were asked to babywear their children for at least three hours a day for the two-month period of the study. The period of two months was chosen based on Melnyk et al.'s 
work studying maternal anxiety and depression (Melnyk, Crean, Feinstein, \& Fairbanks, 2008). Approximately two months after a NICU discharge, initial survival issues are resolved and families are settling in to their "new normal". However, mothers and fathers of preterm babies experience higher levels of stress and anxiety than mothers and fathers of term babies (OlshtainMann \& Auslander, 2008). The time period of three hours a day was chosen based on information gathered in Reynolds et al., 2013 study on parental visitation and holding and its effects on neurobehavior. This study focused on infants born before 30 weeks gestation. More holding was associated with higher quality of movement scores, lower hypertonia, lower infant stress, arousal, and excitability (Reynolds et al., 2013).

\section{Education}

Babywearing is not a common parenting technique in the population of caregivers with children in the NICU at TCH. This necessitated the researcher to recruit participants and educate them about babywearing. One participant had planned to babywear while she was pregnant, but had not done so previously. Of the retained participants, fifty percent had heard of babywearing before, and fifty percent had not. Seventy-five percent were able to hold their infants skin-to-skin while in the NICU and twenty-five percent were not. No retained participants had ever used a baby carrier before.

The lack of previous babywearing studies involving NICU caregivers necessitated the development of appropriate educational material (Appendix $\mathrm{H})$. The caregiver education was developed by the researcher with references from Babywearing International, a non-profit organization whose purpose is to promote babywearing through education and support (Muhd, 2018).

The participants were introduced to four types of carriers. Woven wraps, ring slings, meh 
dais with wrap straps, and buckle carriers. For the purposes of this study, only carriers that had passed testing for soft infant baby carriers were used (CPSC, 2018). Only carriers that resulted in the infant being positioned in kangaroo position were used. Because the great majority of study participants were inexperienced in using baby carriers, woven wraps and wrap conversion ring slings were used to facilitate good positioning. Woven fabric, in general, supports weight more easily than other types of materials and may require less adjusting during wear.

Woven wraps. Woven wraps consist of a length of woven fabric. The front-wrap-crosscarry (FWCC) is a beginner's carry and was the carry taught to study participants (BWI.org, 2018a). FWCC creates a pocket of fabric at the caregiver's chest. The baby has three "passes" of fabric over their trunk. There is no fabric between the infant and caregiver's chests.

Ring slings. In this study, wrap conversion ring slings were used. Ring slings consist of a length of fabric with two metal rings at one end (BWI.org, 2018b). The fabric is threaded through the rings in a way that allows the caregiver to tighten and loosen the fabric to achieve optimal kangaroo position. The front carry position was the carry taught to study participants.

Meh dais. The meh dais used in this study are modifications of a traditional baby carrier native to China. It consists of a center fabric panel with shoulder straps at the top and waist straps at the bottom (BWI.org, 2018c). The width of the panel can vary. For this study, only meh dais with wide straps or "wrap straps" were used and the front passes were stretched over the infant. This technique ensures there are no unsupported areas of the infant's trunk. The meh dais used for this study were capable of cinching down to five inches in width at the bottom of the panel. This function is important when fitting very small infants in carriers since the carrier should not extend past the bend of the knee. Kangaroo position requires the knees to be bent at a natural angle. 
Buckle carriers. Buckle carriers consist of a center fabric panel with shoulder straps that resemble a back pack, but worn on the caregiver's chest (BWI.org, 2018d). Buckle carriers can be difficult to fit very small babies. This study utilized a buckle carrier with an internal harness and narrow width for holding very small babies up high in the panel to achieve kangaroo position. The harness involves a layer of fabric between the infant and the caregiver, unlike the woven wrap, ring sling, or meh dai. The use of infant inserts utilized in other buckle carriers have the potential to complicate positioning for premature infants and were not used in this study.

Each carrier type was demonstrated by the researcher. Afterwards, the participant tried on the carriers with a weighted doll. Once they chose a carrier, and with the inpatient nurse at the bedside, the participant was assisted in fitting their infant in the carrier and instructed to sit at the bedside. Daily carrier use began at discharge.

Because preterm infants typically exhibit low muscle tone, they are more susceptible to chin-to-chest positioning which can allow rebreathing of exhalations causing hypercarbic respiratory depression. Low muscle tone also puts infants at higher risk for physical narrowing of the airway leading to positional asphyxia (Galland \& Elder, 2014). To limit these risks during holding, the World Health Organization guidelines for Kangaroo Care positioning were followed (Appendix B) which includes natural flexing of the knees, hips, and arms, the head turned to one side and slightly extended, and the top of the baby carrier just under the baby's ear (WHO, 2003). This is the position that caregivers typically adopt when holding infants in-arms.

Participants were instructed to prevent large neck flexion or extension, and that infant breathing should be calm and silent. 


\section{Data Collection}

Data was collected to determine approximate amounts of time that babies were worn after NICU discharge. Communication via phone or text messaging once a week between researcher and participant helped approximate the amount of time spent wearing. Wearing by any caregiver was encouraged in order to facilitate self-care for the primary caregiver, but not included in study hours.

The interviewer piloted the interview questions using a NICU caregiver not involved in the study. The interview was recorded and transcribed to identify any potential problems and to ensure good flow with the interview conversation. The interview questions were also answered by the interviewer in order to reduce any biases experienced by the interviewer during interviewing. Brief field notes were taken during interviews to ensure the participants had the full attention of the interviewer, an important characteristic of transcendental phenomenology.

Semi-structured interviews, as defined by Offredy and Vickers (2010), were completed around day sixty of the study. Interviews were audio-recorded and transcribed with the participants' consent. Both a voice recorder and a recording accessory on a laptop were used to record the interviews. Study interviews began as a fixed set of open-ended questions (Appendix D). Participants were encouraged to discuss in detail any subject they wished. Interviews lasted an average of seventeen minutes.

Verbal interactions do not consist only of words but also non-word vocalizations, repetitions, and other sounds that communicate meaning. When verbal interactions are transcribed using verbatim transcription, there is a risk of portraying participants as inarticulate or faltering in their speech. However, verbatim transcription allows for more detailed portrayals of interactions. Interview dynamics can be more easily conveyed using this approach (Bailey, 
2008). The interviewer used a verbatim transcription approach and recorded field notes to bring more detail to the experience of the interviews. Transcribed interviews were listened to and read several times by the interviewer. Due to time constraints and difficulties maintaining participant contact, transcripts of the interviews were not returned to the study participants for comment. Transcribed interviews were coded for this phenomenological study to identify themes of parental experiences (Appendix J).

\section{Introduction of Participants}

All participants were approached in person by the researcher, or had contacted hospital staff inquiring about the study. Six of the eight interviewed participants lived within 20 miles of TCH. One participant lives 124 miles east, and one participant lives 72 miles west of TCH. Participants were not asked about annual income, however, using zip codes to approximate household income the average individual income was $\$ 37,000$ (IRS.gov, 2015). Median income for Oklahoma in 2017 was $\$ 51,000$ (OK.gov, 2017).

The great majority of participants were female, and the mother of the NICU graduate. Three quarters of the participants were white and one quarter Hispanic. Both study percentages are higher than race and ethnicity percentages for white and Hispanic Oklahomans estimated in the 2010 census (Census.gov, 2011). No other ethnicities were retained throughout the interview. This study included male caregivers as $20 \%$ of the enrolled participants. However, two fathers were lost through study attrition, and one was retained through the interview process. 
Table 1

\section{Demographics of Study Participants}

\begin{tabular}{lcc}
\hline Caregiver Characteristics & N (\%) 15 Enrolled & N(\%) 8 Interviewed \\
\hline Gender & $12(80)$ & $7(88)$ \\
Female & $3(20)$ & $1(12)$ \\
Male & & \\
& & \\
Ethnicity & $10(67)$ & $6(75)$ \\
White & $3(20)$ & $2(25)$ \\
Hispanic & $2(13)$ & $0(0)$ \\
Native American &
\end{tabular}

Oklahoma Ethnic and Race Percentages (Census.gov, 2011).

White

Black or African American

Hispanic

Native American

Asian

Two or more races

Age

$20-25$

26-30

$31-35$

$36-40$

41

\# of Children $<18$ excluding neonate

0

1

3

4

5

Participated in $\mathrm{KC}$ in NICU

Yes

No

$12(80)$

$3(20)$

$5(33)$

$4(27)$

$3(20)$

$1(7)$

2 (13)

(2)

$3(20)$

$4(27)$

$5(33)$

1 (7)

2 (13)

$1(12)$

$1(12)$

$3(38)$

$1(12)$

$2(25)$

$5(63)$

$1(12)$

$1(12)$

$1(12)$

$0(0)$

Knowledge of BW before NICU

Yes

No

Used a baby carrier before NICU

Yes

No
$6(40)$

$9(60)$

$1(7)$

$14(93)$
$6(75)$

$2(25)$

$4(50)$

$4(50)$

$0(0)$

8 (100) 


\section{Location Chosen by Participant to Interview}

Participant home 2

Hospital 2

Public coffee shop 3

Phone 1

\begin{tabular}{lll}
\hline Infant Characteristics & N (\%) 15 Enrolled & N(\%) 8 Interviewed
\end{tabular}

Gestational Age

$\begin{array}{lll}28.4-29.6 \text { weeks } & 2(13) & 0(0) \\ 30-33 \text { weeks } & 6(40) & 4(50) \\ 34-37 \text { weeks } & 4(27) & 4(50) \\ 38 \text { weeks } & 1(7) & 0(0)\end{array}$

Birth weight

$\begin{array}{lll}\text { Normal }>2500 \mathrm{~g} & 4(27) & 4(50) \\ \text { LBW }<2500 \mathrm{~g} & 7(47) & 4(50) \\ \text { VLBW }<1500 \mathrm{~g} & 4(27) 2 \text { sets of twins } & 0(0) \\ \text { ELBW }<1000 \mathrm{~g} & 0(0) & 0(0)\end{array}$

\section{Data Analysis}

The semi-structured interview data was analyzed using a phenomenological approach in order to understand the meaning of how babywearing affects caregivers after a NICU discharge. If themes similar to kangaroo care research are identified, then babywearing may be capable of producing similar results as skin-to-skin or kangaroo care.

Coding was used to identify themes. All answers to each study question were viewed as a group. Interviews were also listened to multiple times during the transcription process. Some study themes became apparent after three interviews such as Ease of Work while other themes took longer to appear such as Empowerment and Decreased Stress and Anxiety. 


\section{CHAPTER FOUR}

\section{Results and Discussion of Results}

Contact was maintained during the study by communicating and documenting the number of hours spent wearing per week. Week 0 counted from their discharge date until the following Saturday evening. Week 1 began with the first Sunday morning after discharge. Participants chose how to track their hours. Participant 1 maintained a spreadsheet and entered data on a daily basis. Participant 12 kept a mental log and relayed estimates of hours worn per week to the researcher. One study question asked how many hours per day they used the carrier. Participant estimations during the study approximately matched their answers to that study question.

Once the participants began using the carrier at home, all but one increased their hours for at least the first two weeks. This may be a measure of increased comfort with using the carrier, or perhaps recognition of the benefits of using the carrier to complete tasks or decrease infant crying. These benefits are discussed further under the Themes.

The researcher was made aware of a study bias not apparent before data collection. The researcher assumed that a lower number of hours spent wearing would reflect a lower enjoyment of wearing, or lower perception of benefit. Participant 12 reported the lowest numbers of hours spent wearing, yet her interview revealed similar themes to other participants including Ease of Work, Calmness and Sleep, and Bonding. She stated, "It was great! It helps me because he's right there on my chest, I mean, that's it." A second revealed bias was that participants with more children to care for may log lower hours. Participant 6 is a single mother with five children under the age of 18. She logged ninety more hours than any other participant in the study. Participant 
16 logged the second highest number of hours spent wearing and was the only other participant caring for another child under the age of 18 .

\section{Themes}

Six themes were identified in this study. While two of these themes appear to be independent to this study, four themes share similarities to kangaroo care or skin-to-skin research.

\section{Themes Similar to Kangaroo Care}

Decreased Stress and Anxiety. Caring for a child in the NICU can be very stressful for caregivers. In addition to being away from home, caregivers are faced with their child's mortality soon after birth. Fear of loss is common in NICU caregivers. Two participants verbalized that babywearing relieved anxiety related to possible loss. Participant 10 verbalized fear of losing her child through kidnapping and that using a carrier helped her worry less. Participant 7's infant experienced an apneic episode that did not resolve when she picked her up from her crib. After a few rescue breaths she aroused. This participant experienced renewed fear of loss after discharge. She verbalized that using the carrier during the day helped her worry less because her infant stayed with her. Participant 7 said, "I don't have to worry about her" and participant 16 said, "My baby is safe with me." Emotional and physical recovery after discharge from the NICU for the caregiver is an important task and babywearing could help support this.

NICU caregivers are justifiably anxious about germs and their immune compromised, premature children. Participant 6 stated, "I was able to keep her safer from germs in public. She hasn't gotten sick!" and Participant 10 said, "People are not as likely to touch her in public. It's flu season." Rates of infection between infants who are worn or not worn is a compelling research opportunity. 
Parents of children discharged from the NICU experience the same rate of PTSD symptoms as individuals who have experienced a traumatic event. As PTSD can hinder the process of bonding, skin-to-skin care can promote bonding (Vanderbilt et al., 2009).

Babywearing is likely to produce the same or similar result in respect to reduction of anxiety and promotion of bonding between caregiver and child.

Calmness and Sleep. All participants verbalized that their infants were calmer, less fussy, cried less, and slept more in the carriers. Participant 1 said "she goes right to sleep" and participant 16 said, "he sleeps here" (gesturing towards her chest). Participant 14 said not only did her baby fall asleep in the carrier, he would sleep until she took him out. Premature children need more sleep than term children but also need to feed more often than term children. This makes it the infant's job to eat and sleep on a nearly continual basis. This can be a difficult schedule for caregivers to maintain when they have competing responsibilities. Participant 16 explained that she was able to breastfeed her infant while he was in the carrier. Research has linked increased daytime sleeping in preterm infants with positive social emotional development and resilience processes (Schwichtenberg, Shah, \& Poehlmann, 2013). Being able to feed and promote sleep while babywearing can be a useful tool for caregivers of premature infants.

Bonding. Participant 6 said, "I feel like I bonded with her more.” Participant 14 stated, "It's a different experience [from her other children] and you get to bond with them more." While all the participants didn't use the term bonding, they did all describe positive bonding experiences. For example, participant 1 said, “It just feels SO good, it's just such a feeling of love, like you and your baby are hugging." Participant 7 said, "I felt closer to her. She loves to be held like that." Participant 10 said, "I love having her strapped on and she seems to really love 
it." Participant 16 stated, "It's more time with my baby." All participants spoke in loving terms of their infants.

Empowerment. A common struggle for new parents is saying no to friends and family that want to hold their premature baby. Premature babies are often discharged before their expected due date (EDD). Being exposed to environments outside of the mother's body before the EDD puts infants at risk for infection, stress, and injury. Participant 1 verbalized that wearing her daughter in the carrier gave her confidence to say no when other people wanted to hold her. Participant 10 described her interaction with a stranger who touched her daughter's hair. She firmly asked, "Can you not?" Participants verbalized experiences of telling people around them, no. The ability for caregivers to say no to potentially harmful experiences is very important to decrease stress and anxiety for caregivers, and decrease risk for the child.

Participant 14 was experiencing a PICU admission with her youngest son at the time of the interview. She was experiencing difficulties communicating with her healthcare team and verbalized, "They might, the doctors might say another word and everything, but I think we've already come to the conclusion. The doctors, they don't know what we go through day in, day out." Communicating with healthcare professionals during a child's hospitalization can be a daunting and intimidating experience. Caregivers need the confidence and self-reliance to voice their opinions, concerns, and desires for their child, and the expectation that they will be heard by their healthcare team.

\section{Unique Themes}

Ease of Work. All eight interviewed participants mentioned that using carriers made things easier. Seven participants mentioned house maintenence in particular. Participant 12 stated that the carrier helped her complete household tasks. Participant 10 mentioned the car seat is 
heavy and it's easier "having her strapped to me". Participant 13 said, "Instead of having to roll him around, I can carry him." Participant 14 mentioned use of public transportation is much easier while babywearing as opposed to using a stroller.

Self-Care. Infancy is an intense time for caregivers and premature children can be even more intense in their needs and time requirements. Participant 1 stated that using the carrier helped her to eat, as her hands were free. Participant 7 explained that she felt able to "put on makeup and do up [her] hair" and that this made her feel better about the day, even if she wasn't going anywhere. Participant 12 stated, "I do what I need to do." Participant 10 was able to play a video game when she wasn't studying or attending her college courses. Participant 13 deals with chronic back pain which can be exacerbated by carrying children. He stated that using the carrier takes the "weight off his back" when he is carrying his son.

\section{Diverse Cases and Minor Themes}

Participant 13 was a diverse case related to gender. He spoke more about ease of use, and mentioned perception of others regarding using a baby carrier. Answering "What is it like to be someone who uses a baby carrier”, he said, “Normal. I don't see why people would feel embarrassed about wearing it. I've actually had two people ask me what it was and I told them, it's just something I hold my son in. Instead of having to roll him around, I can carry him.” Participant 6 relayed an example of a man asking her if her carrier looked, "girly” because he would like to use one when he has a baby. These two exemplars suggest a lack of data saturation for men who use baby carriers. There is evidence that gender equality is a support for successful KC with fathers (Varela, Muńoz, Tessier, Plata, \& Charpak, 2014). It is probable that gender equality may also support fathers to babywear. 


\section{CHAPTER 5}

\section{Discussion}

The similar themes of Decreased Stress and Anxiety, Calmness and Sleep, Bonding, and Empowerment are compelling reasons for healthcare professionals to encourage caregivers to continue holding their children as much as possible after their hospital discharge. Using a baby carrier allowed caregivers to hold and comfort their child without losing the use of their hands to cook, clean, care for other children, and decreased their need for heavy equipment such as strollers or carried car seats.

Neonatal ICUs continue to struggle with implementation of kangaroo care due to many problems including caregiver presence and inadequate NICU staffing. Babywearing could be offered as a way for caregivers to redeem lost time with their infants. In addition, the themes of Calmness and Sleep, Bonding, Decreased Stress and Anxiety, and Empowerment hold the potential to improve quality of life for both the caregiver and the infant.

Dr. Nils Bergman, a physician specializing in and promoting kangaroo care in South Africa states, "The mother's body is the only natural environment for the premature infant." (Olanders, 2004, pg. 1). Kangaroo care and babywearing can be used together as an intervention to improve patient and caregiver outcomes in families experiencing NICU admissions.

\section{Statement of the Significance of the Findings}

It was expected that babywearing could provide similar benefits as skin-to-skin and kangaroo care in the area of decreasing parental stress and anxiety and increasing parental confidence and empowerment. The study results support that babywearing has the potential to decrease caregiver stress and anxiety, increase calming and sleep for the infant, and promote bonding and caregiver empowerment. If babywearing is capable of mitigating the iatrogenic harms of NICU hospitalizations then the benefits of decreased readmission rates, decreased 
infant irritability, increased infant and parental resilience, and improvement in health of the infant should be measured.

\section{Contributions to Research}

There are very few research studies regarding the use of baby carriers, and no research studies on the use of baby carriers with premature children. This study provided new insight about the similarities between kangaroo care and babywearing not previously studied. There are many opportunities to learn more about babywearing as an extension of kangaroo care after a NICU discharge through additional qualitative and quantitative research.

\section{Implications}

Babywearing as a parenting tool is practiced by caregivers in many areas of the world. The unique characteristics of premature infants prevent even experienced caregivers from being able to draw from past experiences or receive good advice from friends and family. Premature infants are at higher risk for infection, injury, SIDS, hypothermia, overstimulation, and neurodevelopmental problems. The high needs of premature children can lead to increased stress and anxiety in addition to the anxiety experienced by parents having begun their current parenting experience in neonatal intensive care. Using a baby carrier has the potential to be a low risk, high return intervention for caregivers of premature infants.

While it may be intuitive to recommend babywearing as a way to help caregivers promote sleep, calming, and decrease crying for their neonates, additional research could help answer deeper questions. Research could investigate if babywearing results in improved neurodevelopment in a similar way that kangaroo care does. Healthcare professionals who work with NICU families also need to know how many hours a day of babywearing is enough to result in benefits. 


\section{Limitations of Findings}

This study involved caregivers predominantly from the Oklahoma City metro area. While it is likely that the results can be applied to NICU caregivers living outside this metro area, other populations should be studied. Lack of diversity continues to be a problem in research (Oh, et al., 2015). While this study was able to include caregivers who identify as Hispanic, other minority populations were not represented. Efforts should be made to include researchers from minority and vulnerable populations in order to increase participation of these same populations. There were both one male participant, and one grandparent. Data saturation was not met for fathers or grandparents as caregivers of premature infants. There is a high importance for fathers and primary care grandparents to be included in NICU research. The great majority of research in the NICU focuses on mothers only.

This study experienced an attrition rate of approximately $47 \%$. Attrition rates are higher when research data collection occurs after a hospital discharge. There is a potential for bias in that the participants who were retained may have derived greater benefits from babywearing, and thus made themselves available for interviews. Approximately eight weeks following study completion, letters requesting reconnection were mailed to each participant with whom contact had been lost, but this effort did not result in renewed contact with the researcher. An alternate study protocol may make reduced attrition possible. While this study may result in bias related to attrition, all participants who made contact during the study verbalized that babywearing was going well and that their babies enjoyed it. Participant 11 requested a home visit to try a different carrier during week seven of the study. She traded a ring sling for a woven wrap and a meh dai and verbalized satisfaction with those carriers. She maintained contact for approximately five weeks after the study was over but the researcher was unable to retain the interview. Participant 2 
was particularly motivated in the study. During her twins' hospitalization she encouraged three other NICU caregivers to join the study. She is Native American and recruited another Native American mother. There were three weeks from study enrollment to NICU discharge. After discharge this participant experienced contracting influenza, the loss of a close family member, and a hospital readmission for one of her twins. During the study period she maintained a high number of hours worn and verbalized that she involved other family members in babywearing her twin infants. Despite loss to attrition before the interview, it is probable that even participants who were not interviewed may have had positive experiences with babywearing.

A qualitative study design was chosen due to the lack of previous babywearing studies in the premature population and limited studies in any population. It will be interesting for quantitative research to be measured particularly with use of proven scales of depression, anxiety, and stress already measured in kangaroo care populations, such as the Parent Stressor Scale (PSS:NICU), the Parental Belief Scale (PBS: NICU), Perinatal PTSD Questionnaire (PPQ), State-Trait Anxiety Inventory (STAI), and Beck Depression Inventories (BDI).

\section{Areas of Future Research}

\section{Empowerment}

There are few interventions in place to promote parental and caregiver empowerment for the premature infant's family. Research is needed to determine if babywearing can promote caregiver empowerment, and how positive caregiver empowerment can help families of NICU graduates.

\section{Decreased Stress and Anxiety}

Caregivers of NICU graduates experience higher levels of stress and anxiety than caregivers of term infants. Kangaroo care reduces stress and anxiety for parents. But we do not 
know how babywearers of NICU graduates might score on measures of stress, anxiety, depression and PTSD. In addition, it would be beneficial to know how babywearing affects levels of stress and anxiety for the infant and what effects this may have on infant growth and development.

\section{Paternal Roles}

Because men fulfill such a unique role in the lives of their children, additional research should be pursued regarding if babywearing can provide similar results as $\mathrm{KC}$ in fathers such as decreased stress, higher parental involvement, and more caring behaviors (Varela, Muńoz, Tessier, Plata, \& Charpak, 2014). If babywearing encourages bonding and facilitates paternal role attainment, fathers may remain more involved with their children. Research is also needed to discover ways to decrease the impact of gender bias in fathers who babywear their children.

\section{Potential to Decrease Risks of Daytime Sleeping}

Premature babies have a significantly higher risk of succumbing to SIDS (Ostfeld, Schwartz-Soicher, Reichman, Teitler, \& Hegyi, 2017). Babywearing has the potential to ease the difficulty of following safe sleep guidelines by replacing an artificial sleep surface with the caregiver's chest. Babywearing during daytime infant sleep could discourage the use of infant equipment not approved for sleep such as car seats, rockers, or other unsafe sleep surfaces.

\section{Potential to Decrease Musculoskeletal Issues}

Study participants described infants sleeping while being carried. Premature infants experience plagiocephaly, brachycephaly, and torticollis related to supine positioning at higher rates than term infants (Sweeney \& Gutierrez, 2002). These maladaptive musculoskeletal changes are difficult to treat. Research is needed to determine if carrying could decrease the rates of plagiocephaly and other musculoskeletal problems experienced by NICU graduates. 


\section{Potential to Decrease Exposure to Pathogens}

Caregivers of NICU graduates are typically advised to limit their baby's exposure to public environments until they are older, especially during flu, pneumonia, and RSV season. If babywearing can result in limitations in pathogen exposure for the worn infant, then the possibility for decreased risk of neonatal and infant infections experienced by premature children should be studied.

\section{In Closing}

There are unique opportunities for healthcare professionals and caregivers of premature infants to work together to lessen negative sequelae of spending time in the neonatal intensive care unit. Benefits are possible in varied areas such as neurodevelopment, musculoskeletal issues, psychosocial connections, and easing the work of parenting.

The limited research available on babywearing and the use of baby carriers highlights a gap in knowledge and in evidence. The benefits of skin-to-skin care and kangaroo care are well researched and documented (Nyqvist et al., 2010). The inconsistent application of the research supporting skin-to-skin and kangaroo care continues to be problematic (Kymre, 2014; Ludington-Hoe, 2011). Using babywearing as a tool to mitigate negative effects of NICU hospitalizations for the infant and caregivers is a compelling area of research that should provide many positive and interesting results. 


\section{REFERENCES}

Als, H., \& McAnulty, G. B. (2011). The Newborn Individualized Developmental Care and Assessment Program (NIDCAP) with Kangaroo Mother Care (KMC): Comprehensive care for preterm infants. Current Women's Health Reviews, 7(3), 288-301. doi:10.2174/157340411796355216

Anisfeld, E., Casper, V., Nozyce, M., \& Cunningham, N. (1990). Does infant carrying promote attachment? An experimental study of the effects of increased physical contact on the development of attachment. Child Development, 61(5), 1617-1627. doi:10.2307/1130769

Bailey, J. (2008). First steps in qualitative data analysis: Transcribing. Family Practice,25(2), 127-131. doi:10.1093/fampra/cmn003

Bergström, A., Okong, P., \& Ransjö-Arvidson, A. (2007). Immediate maternal thermal response to skin-to-skin care of newborn. Acta Paediatrica,96(5), 655-658. doi:10.1111/j.16512227.2007.00280.x

Blencowe, H., Cousens, S., Oestergaard, M., Chou, D., Moller, A., Narwal, R., . . Lawn, J. (2013). National, regional, and worldwide estimates of preterm birth rates in the year 2010 with time trends since 1990 for selected countries. The Lancet, 379, 2162-2171. doi:10.1097/01.aoa.0000432360.25014.c3

Blomqvist, Y., Frölund, L., Rubertsson, C., \& Nyqvist, K. (2013). Provision of Kangaroo Mother Care: Supportive factors and barriers perceived by parents. Scandinavian Journal of Caring Sciences, 27(2), 345-353. doi: 10.1111/j.1471-6712.2012.01040.x

Blomqvist, Y., Rubertsson, C., Kylberg, E., Jöreskog, K., Nyqvist, K. (2012). Kangaroo Mother Care helps fathers of preterm infants gain confidence in the paternal role. Journal of Advanced Nursing, 68,(9), 1988-1996. doi: 10.1111/j.1365-2648.2011.05886.x 
Burnham, N., Feeley, N., \& Sherrard, K. (2013). Parents' perceptions regarding readiness for their infant's discharge from the NICU. Neonatal Network, 32(5), 324-334.

Burns, N., \& Grove, S. K. (2011). Introduction to the qualitative research process. In N. Burns \& S. K. Grove (Ed.), Understanding nursing research: Building an evidence-based practice (5th ed.) (pp. 72-100). Maryland Heights, MO: Elsevier Saunders.

BWI.org. (2018a). Beginner Carries. Retrieved April 21, 2018, from https://babywearinginternational.org/what-is-babywearing/babywearingresources/beginner-carries/

BWI.org. (2018b). Ring Sling. Retrieved April 21, 2018, from https://babywearinginternational.org/what-is-babywearing/babywearing-resources/ringsling/

BWI.org. (2018c). Meh Dai / Bei Dai. Retrieved April 21, 2018, from https://babywearinginternational.org/what-is-babywearing/babywearing-resources/meitai/

BWI.org. (2018d). Buckle Carrier. Retrieved April 21, 2018, from https://babywearinginternational.org/what-is-babywearing/babywearingresources/buckle-carriers/

Census.gov. (2011, May 05). US Census Bureau 2010 Census Interactive Population Map. Retrieved April 14, 2018, from https://www.census.gov/2010census/popmap/ipmtext.php?fl=40

Chan, G. J., Labar, A. S., Wall, S., \& Atun, R. (2016a). Kangaroo mother care: A systematic review of barriers and enablers. Bulletin of the World Health Organization, 94(2), 130141J. doi: http://dx.doi.org/10.2471/BLT.15.157818. 
Chan, G. J., Valsangkar, B., Kajeepeta, S., O'Boundy, E., Wall, S. (2016b). What is kangaroo mother care? Systematic review of the literature. Journal of Global Health, 6(1), e1-9. doi: 10.7189/jogh.06.010701.

Charpak, N., Ruiz-Pelaez, J. G., Figueroa, Z., \& Charpak, Y. (1997). Kangaroo mother versus traditional care for newborn infants $\leq 2000$ grams: A randomized controlled trial. Pediatrics, 100(4), 682-688.

Charpak, N., Tessier, R., Ruiz, J., Hernandez, J. T., Uriza, F., Villegas, J. . . Maldonado, D. (2017). Twenty-year follow-up of Kangaroo Mother Care versus traditional care. Pediatrics, 139(1).

CPSC.gov. (2018). Soft Infant and Toddler Carriers Business Guidance \& Small Entity Compliance Guide. Retrieved April 21, 2018, from https://www.cpsc.gov/Business-Manufacturing/Business-Education/Business-Guidance/Soft-Infant-and-Toddler-Carriers

Creswell, J. W., \& Poth, C. N. (2018). Qualitative inquiry \& research design: Choosing among five approaches. Thousand Oaks, CA: SAGE.

DOL.gov. (n.d.). Family and Medical Leave Act. Retrieved April 15, 2018, from https://www.dol.gov/whd/fmla/

Erdeve, O., Arsan, S., Yigit, S., Armangil, D., Atasay, B., \& Korkmaz, A. (2008). The impact of individual room on rehospitalization and health service utilization in preterms after discharge. Early Human Development, 97(10), 1351-1357. doi:10.1016/j.earlhumdev.2008.09.121

Feeley, N., Genest, C., Niela-Vilén, H., Charbonneau, L., \& Axelin, A. (2016). Parents and nurses balancing parent-infant closeness and separation: A qualitative study of NICU nurses' perceptions. BMC Pediatrics, 16(1). doi:10.1186/s12887-016-0663-1 
Fusch, P., \& Ness, L. (2015). Are we there yet? Data saturation in qualitative research. The Qualitative Report, 20(9), 1408-1416.

Galland, B., \& Elder, D. (2014). Sudden unexpected death in infancy: Biological mechanisms. Paediatric Respiratory Reviews, 15(4), 287-292.

Greenfield, J. C., \& Klawetter, S. (2016). Parental leave policy as strategy to improve outcomes among premature infants. Health \& Social Work, 41(1), 17-23.

Guralnick, M. J. (2012). Preventive interventions for preterm children. Journal of Developmental \& Behavioral Pediatrics, 33(4), 352-364. doi:10.1097/dbp.0b013e31824eaa3c

Husmillo, M. (2013). Maternal role attainment theory. International Journal of Childbirth Education, 28(2), 46-48.

IRS.gov. (2015). Tax Statistics. Retrieved April 10, 2018, from https://www.irs.gov/statistics

Kim, W. J., Lee, E., Kim, K. R., Namkoong, K., Park, E. S., \& Rha, D. (2015). Progress of PTSD symptoms following birth: A prospective study in mothers of high-risk infants. Journal of Perinatology, 35(8), 575-579. doi:10.1038/jp.2015.9

Kuo, D. Z., Houtrow, A. J., Arango, P., Kuhlthau, K. A., Simmons, J. M., \& Neff, J. M. (2011). Family centered care: Current applications and future directions in pediatric health care. Maternal Child Health Journal, 16, 297-305.

Kymre, I. G. (2014). NICU nurses' ambivalent attitudes in skin-to-skin care practice. International Journal of Qualitative Studies on Health and Well-Being, 9. doi:10.3402/qhw.v9.23297

Ludington-Hoe, S. (2011). Thirty years of kangaroo care science and practice. Neonatal Network,30(5), 357-362. 
MacDorman, M. F., \& Gregory, E. C. (2015). Fetal and Perinatal Mortality: United States, 2013. National Vital Statistics Reports, 64(8), 1-23. Retrieved from http://www.cdc.gov/nchs/data/nvsr/nvsr64/nvsr64_08.pdf

Martin, J. A., Hamilton, B. E., \& Osterman, M. J. (2015). Births in the United States, 2014. Retrieved December 05, 2016, from http://www.cdc.gov/nchs/nvss/births.htm

Melnyk, B. F., Crean, H., Feinstein, N., \& Fairbanks, E. (2008). Maternal anxiety and depression after a premature infant's discharge from the neonatal intensive care unit: Explanatory effects of the Creating Opportunities for Parent Empowerment program. Nursing Research, 57(6), 383-394.

Muhd, T. (2018). Babywearing International. Retrieved from https://babywearinginternational.org/

Nyqvist, K., Anderson, G., Bergman, N., Cattaneo, A., Charpak, N., Davanzo, R., ...Widström, A. (2010). Towards universal Kangaroo Mother Care: Recommendations and report from the first European conference and seventh international workshop on Kangaroo Mother Care. Acta Paediatrica, 99(6), 820-826. http://dx.doi.org/10.1111/j.16512227.2010.01787.x

Offredy, M., \& Vickers, P. (2010). The research proposal: Collecting data. In M. Offredy \& P. Vickers (Ed.), Developing a healthcare research proposal: An interactive student guide (pp. 152-177). Ames, IA: Wiley-Blackwell. 
Oh, S., Galanter, J., Thakur, N., Pino-Yanes, M., Barcelo, N., White, M., . . . Burchard, E. (2015). Diversity in clinical and biomedical research: A promise yet to be fulfilled. PLOS Medicine, 12(12), E1001918.

OK.gov. (2017). Median household income. Retrieved April 14, 2018, from https://data.ok.gov/dataset/median-household-income

Olanders, M. (2004). The mother's body is the only natural, healthy environment for a new baby. Retrieved April 14, 2018, from http:/www.kangaroomothercare.com/olanders.aspx

Olshtain-Mann, Orly, \& Auslander, Gail K. (2008). Parents of preterm infants two months after discharge from the hospital: Are they still at (parental) risk? Health \& Social Work, 33(4), 299-308.

Ostfeld, B., Schwartz-Soicher, O., Reichman, N., Teitler, J., \& Hegyi, T. (2017). Prematurity and Sudden Unexpected Infant Deaths in the United States. Pediatrics, 140(1).

OU Medicine. (2016). Neonatal \& Perinatal Services. Retrieved November 30, 2016, from https://www.oumedicine.com/oumedicine/adult-services/women'shealth/pregnancy/neonatal-perinatal-services

Pisacane, A., Continisio, P., Filosa, C., Tagliamonte, V., \& Continisio, G. I. (2012). Use of baby carriers to increase breastfeeding duration among term infants: The effects of an educational intervention in Italy. Acta Paediatrica, 101(10), E434-E438.

Raffray, M., Osorio, S., Ochoa, S. C., Semenic, S., (2014). Barriers and facilitators to preparing families with premature infants for discharge home from the neonatal units. Perceptions of health care providers. Invest Education Enferm 32(3), 379-392. 
Reynolds, L. C., Duncan, M. M., Smith, G. C., Mathur, A., Neil, J., Inder, T., \& Pineda, R. G. (2013). Parental presence and holding in the neonatal intensive care unit and associations with early neurobehavior. Journal of Perinatology, 33(8), 636-641. doi:http://dx.doi.org.vortex3.uco.edu/10.1038/jp.2013.4

Reynolds-Miller, R. L. (2016). Potential therapeutic benefits of babywearing. Creative Nursing, 22(1), 17-23. doi:10.1891/1078-4535.22.1.17

Rimmerman, A., \& Sheran, H. (2001). The transition of Israeli men to fatherhood: A comparison between new fathers of preterm/full term infants. Child and Family Social Work, 6(3), 261-267. doi: 10.1046/j.1365-2206.2001.00201.x

Schwichtenberg, A., Shah, P., \& Poehlmann, J. (2013). Sleep and attachment in preterm infants. Infant Mental Health Journal, 34(1), 37-46.

Shirazi, Z., Sharif, F., Rakhshan, M., Pishva, N., \& Jahanpour, F. (2015). The obstacles against nurse-family communication in Family-Centered Care in Neonatal Intensive Care Unit: A qualitative study. Journal of Caring Science, 4(3), 207-216.

Shorey, S., Hong-Gu, H., \& Mőrelius, E. (2016). Skin-to-skin contact by fathers and the impact on infant and paternal outcomes: An integrative review. Midwifery, 40, 207-217.

Spruill, C. T. (2015). Developmental Support. In M. T. Verklan \& M. Walden (Authors), Core curriculum for neonatal intensive care nursing (5th ed., pp. 193-215). St. Louis, MO: Elsevier Saunders.

Sweeney, S., Rothstein, Ra., Visintainer, P., Rothstein, Ro., \& Singh, R. (2016). Impact of kangaroo care on parental anxiety level and parenting skills for preterm infants in the neonatal intensive care unit. Journal of Neonatal Nursing, 23(3), 151-158. doi:10.1016/j.jnn.2016.09.003 
Sweeney, J. K., \& Gutierrez, T. (2002). Musculoskeletal implications of preterm infant positioning in the NICU. The Journal of Perinatal \& Neonatal Nursing, 16(1), 58-70.

Tahirkheli, N., Cherry, A., Tackett, A., Mccaffree, M., \& Gillaspy, S. (2014). Postpartum depression on the neonatal intensive care unit: Current perspectives. International Journal of Women's Health, 6, 975-987.

Tessier, R., Cristo, M., Velez, S., Giron, M., De Calume, Z. F., Ruiz-Palaez, J. G., . . Charpak, N. (1998). Kangaroo mother care and the bonding hypothesis. Pediatrics, 102(2), E17.

Tessier, R., Tarabulsy, G., Varela, N., \& Pierce, T. (2017). Cortisol and blood pressure levels decreased in fathers during the first hour of skin-to-skin contact with their premature babies. Acta Paediatrica, 107(4), 628-632. doi: 10.1111/apa.14184

Treyvaud, K., Lee, K. J., Doyle, L. W., \& Anderson, P. J. (2014). Very preterm birth influences parental mental health and family outcomes seven years after birth. The Journal of Pediatrics, 164(3), 515-521. doi:10.1016/j.jpeds.2013.11.001

Vanderbilt, D., Bushley, T., Young, R., \& Frank, D. A. (2009). Acute posttraumatic stress symptoms among urban mothers with newborns in the neonatal intensive care unit: A preliminary study. Journal of Developmental \& Behavioral Pediatrics, 30(1), 50-56. doi:10.1097/dbp.0b013e318196b0de

World Health Organization. (2003). Kangaroo mother care: A practical guide. (ISBN 924 159035 1). Retrieved December 5, 2016, from http://apps.who.int/iris/bitstream/10665/42587/1/9241590351.pdf

World Health Organization. (2016). Preterm birth. Retrieved November 30, 2016, from http://www.who.int/mediacentre/factsheets/fs363/en/ 
APPENDICES 


\section{Appendix A}

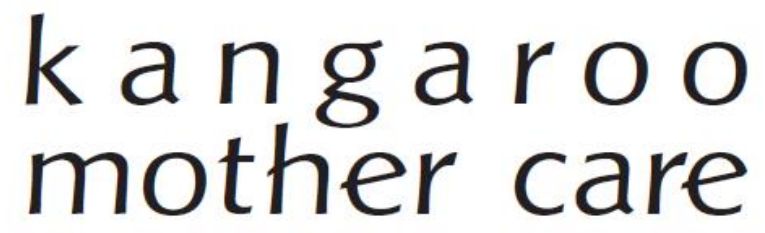

A practical guide

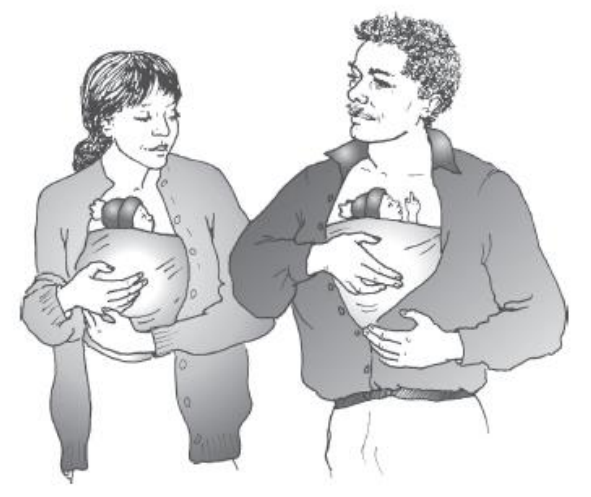

Department of Reproductive Health and Research

Figure 1. Front cover of WHO publication, Kangaroo Mother Care: A practical guide. Retrieved from (http://www.who.int/maternal_child_adolescent/documents/9241590351/en/).

Used with permission.

(Link back to manuscript) 


\section{Appendix B}

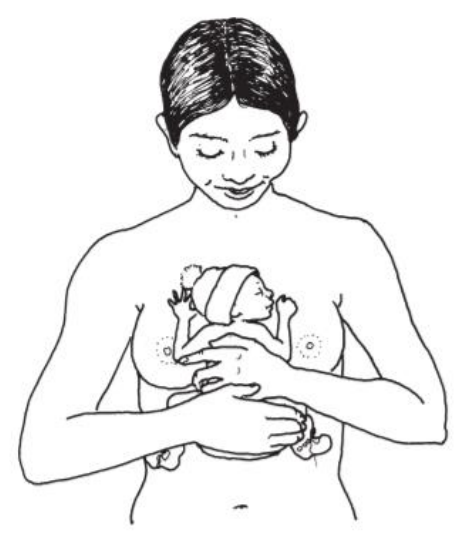

Figure 2. WHO guidelines for Kangaroo Care infant positioning. Retrieved from (http://apps.who.int/iris/bitstream/10665/42587/1/9241590351.pdf). Used with permission.

\section{(Link back to manuscript)}




\section{Appendix C}

From: permissions@who.int [permissions@who.int]

Sent: Tuesday, April 10, 2018 7:17 PM

To: Miller, Robyn L

Cc: permissions@who.int

Subject: ID: 253640 Permission authorization for WHO copyrighted material

\section{Dear Ms Miller}

Thank you for your request for permission to reproduce, reprint or translate certain WHO copyrighted material.

On behalf of the World Health Organization, we are pleased to authorize your request to reproduce the WHO materials as detailed in the form below, subject to the terms and conditions of the non-exclusive licence below.

If you have questions regarding this authorization, please contact permissions@who.int.

We thank you for your interest in WHO published materials.

Kind regards,

WHO Permissions team

\section{WORLD HEALTH ORGANIZATION (WHO)}

\section{Non-exclusive licence to use selected WHO published materials}

You submitted a request, through WHO's online platform, for permission to reprint and reproduce certain WHO copyrighted material (the "Licensed Materials"). This is a legal agreement (the "Agreement") between you and WHO, granting you a licence to use the Licensed Materials subject to the terms and conditions herein.

\section{Read this Agreement in its entirety before using the Licensed Materials.}

By using the Licensed Materials, you enter into, and agree to be bound by, this Agreement.

This licence is granted only for original materials belonging to WHO. If any part of the WHO published materials you wish to reproduce are credited by WHO to a source other than WHO, those materials are not covered by this Agreement and are not part of the Licensed Materials. You are responsible for determining if this is the case, and if so, you are responsible for obtaining any necessary permission from the source of those third-party materials prior to their use. 
If you enter into this Agreement on behalf of an organization, by using the Licensed Materials you confirm (represent and warrant) that you are authorized by your organization to enter into this Agreement on the organization's behalf. In such a case, the terms "you" and "your" in this Agreement refer to, and this Agreement applies to, the organization.

WHO grants this licence to you based on the representations and warranties you made in the licence request you submitted through WHO's online platform. If any of those representations and/or warranties are or become false or inaccurate, this licence agreement shall automatically terminate with immediate effect, without prejudice to any other remedies which WHO may have.

If you have questions regarding this Agreement, please contact permissions@who.int.

1. Licence. Subject to the terms and Conditions of this Agreement, WHO grants to you a worldwide, royalty free, non-transferable, non-sublicensable, non-exclusive licence to use, reproduce, publish, and display the Licensed Materials in the manner and using the media indicated in the Permissions Request Form you submitted to WHO (the "Licensed Use"). This licence is limited to the current edition of your publication. Future editions or a different use of the Licensed Materials will require additional permission from WHO. If your request includes translation into different languages, then non-exclusive permission is hereby granted to translate the Licensed Materials into the languages indicated.

2. Retained Rights. Copyright in the Licensed Materials remains vested in WHO, and WHO retains all rights not specifically granted under this Agreement.

3. Mandatory Acknowledgement. In every instance of the Licensed Use, you must make suitable acknowledgement of WHO, either as a footnote or in a reference list at the end of your publication, as follows:

"Reprinted from Publication title, Vol /edition number, Author(s), Title of article / title of chapter, Pages No., Copyright (Year)."

In addition, If the Licensed Materials originate from the WHO web site, you must also include the URL reference and the date accessed.

Translations of the Licensed Materials should be attributed as follows:

"Translated with permission of the publisher from Publication title, Vol /edition number, Author(s), Title of article / title of chapter, Pages No., Year."

4. Altering or Modifying the Licensed Materials. As part of the Licensed Use, you may minimally alter or adapt figures and tables in the Licensed Materials to match the style of your publication. Any other alteration or modification of the Licensed Materials (including abbreviations, additions, or deletions) may be made only with the prior written authorization of WHO. 
5. Appropriate and Prohibited Uses. You must use the Licensed Materials in a factual and appropriate context. You may not use the Licensed Materials in association with any product marketing, promotional, or commercial activities, including, without limitation, in advertisements, product brochures, company-sponsored web sites, annual reports, or other noneducational publications or distributions.

6. No WHO endorsement. You shall not state or imply that WHO endorses or is affiliated with your publication or the Licensed Use, or that WHO endorses any entity, organization, company, or product.

7. No use of the WHO logo. In no case shall you use the WHO name or emblem, or any abbreviation thereof. Notwithstanding the foregoing, if the WHO name and/or emblem appear as an integral part of the Licensed Materials (e.g. on a map) you may use the name and/or emblem in your use of the License Materials, provided the name and/or logo is not used separately from the Licensed Materials.

8. No Warranties by WHO. All reasonable precautions have been taken by WHO to verify the information contained in the Licensed Materials. However, WHO provides the Licensed Materials to you without warranty of any kind, either expressed or implied, and you are entirely responsible for your use of the Licensed Materials. In no event shall WHO be liable for damages arising from your use of the Licensed Materials.

9. Your Indemnification of WHO. You agree to indemnify WHO for, and hold WHO harmless against, any claim for damages, losses, and/or any costs, including attorneys' fees, arising in any manner whatsoever from your use of the Licensed Materials or for your breach of any of the terms of this Agreement.

10. Termination. The licence and the rights granted under this Agreement shall terminate automatically upon any breach by you of the terms of this Agreement. Further, WHO may terminate this licence at any time with immediate effect for any reason by written notice to you.

11. Entire Agreement, Amendment. This Agreement is the entire agreement between you and WHO with respect to its subject matter. WHO is not bound by any additional terms that may appear in any communication from you. This Agreement may only be amended by mutual written agreement of you and WHO.

12. Headings. Paragraph headings in this Agreement are for reference only.

13. Dispute resolution. Any dispute relating to the interpretation or application of this Agreement shall, unless amicably settled, be subject to conciliation. In the event of failure of the latter, the dispute shall be settled by arbitration. The arbitration shall be conducted in accordance with the modalities to be agreed upon by the parties or, in the absence of agreement, with the rules of arbitration of the International Chamber of Commerce. The parties shall accept the arbitral award as final. 
14. Privileges and immunities. Nothing in or relating to this Agreement shall be deemed a waiver of any of the privileges and immunities enjoyed by WHO under national or international law and/or as submitting WHO to any national court jurisdiction.

$* * *$

DataCol Web: Form for requesting permission to reproduce, reprint or translate WHO copyrighted material

ID: 253640

* Website URL where WHO material is published

$*$

http://apps.who.int/iris/bitstream/handle/10665/42587/9241590351.pdf;jsessionid=BB9B2513A1 C65952F3016BF5C3373011? sequence $=1$

* ISBN / WHO Reference Number

* 9241590351

* Please select the item(s) to be reproduced

* Figure/table

* page 21 , Figure $4 \mathrm{a}$

Section: Information about your publication

* Please provide the title of your publication that the above materials are to be published in

* What is the Experience of Babywearing a NICU Graduate?

Section: Information about WHO material to be reproduced

* Full title of WHO material from which the reproduction is to be made

* Kangaroo mother care: a practical guide

Authors:

World Health Organization, Dept. of Reproductive Health and Research

* Website URL where WHO material is published

* http://www.who.int/maternal_child_adolescent/documents/9241590351/en/

* ISBN / WHO Reference Number

* 9241590351

* Please select the item(s) to be reproduced

* Photo 
* For each item, please provide a reference and page number. If entire document, please state "Entire document".

* The front cover page of the document.

Section: Information about your publication

* Please provide the title of your publication that the above materials are to be published in

* What is the Experience of Babywearing a NICU Graduate?

(Link back to manuscript) 


\section{Appendix D}

\section{Interview Questions}

\section{Textural Description - "What" Questions}

Please talk about any positive and negative experiences with babywearing. What was it like being (baby's name) parent before and after learning about babywearing?

Has the rhythm of your activities of daily living changed before and after learning about babywearing? How?

How many hours a day did you babywear? Did other parents or caregivers also wear (baby's name)?

How did you perceive the requested amount of time per day spent babywearing? (3 hours). Did it seem long or short to you?

\section{Structural Description - "How" Questions}

What is it like to be a babywearer?

What do you see as the benefits and difficulties of babywearing (baby's name)?

Would you recommend babywearing to your friends or your children?

Tell me some words you think describe (baby's name).

Is there anything else you would like to share about your experiences in the NICU?

Is there anything else you would like to share about your experiences babywearing (baby's name)?

Is there anything else you would like to add or share?

\section{(Link back to manuscript)}




\section{Appendix E}

\section{IRB Letter of Approval}

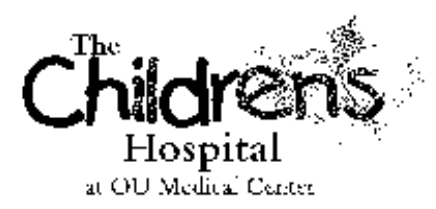

Augush $25^{\text {th }}, 20 ; 17$

lesticutional Rcricu: Boal'd

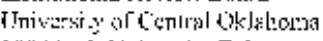

10) Nothlh I! חivetsily Drive

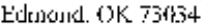

To Whim TI. Yiny C:viltem:

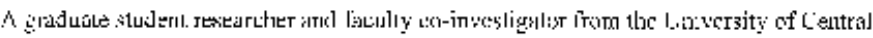

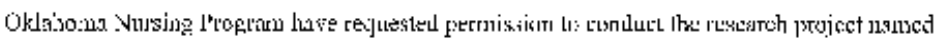

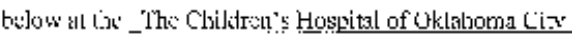
titring, the jeris:

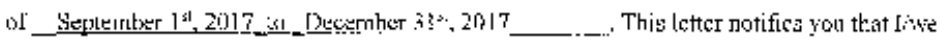

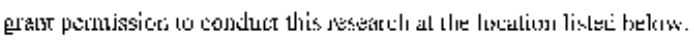

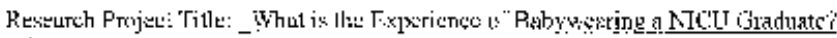

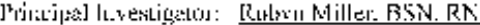

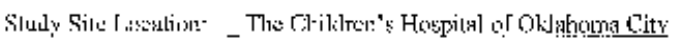

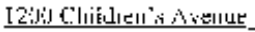

- Wxishor

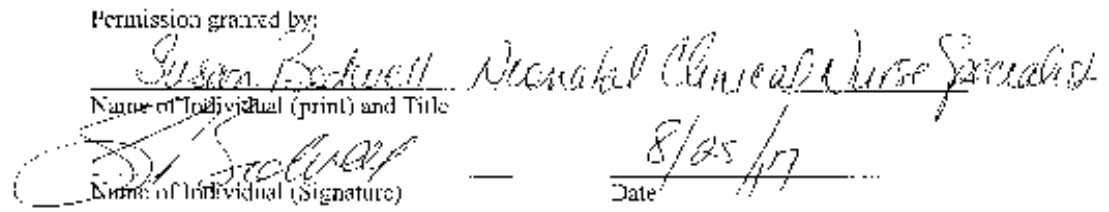

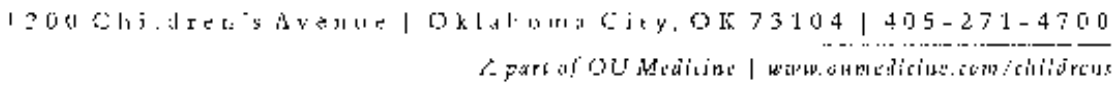

(Link back to manuscript) 


\section{Appendix F}

\section{Consent Form}

\section{University of Oklahoma Health Sciences Center (OUHSC)}

What Is the Experience of Babywearing a NICU Graduate?

\section{Susan Bedwell, MS, APRN, CCNS-N}

This is a research study. Research studies involve only individuals who choose to participate. Please take your time to make your decision. Discuss this with your family and friends.

\section{Why Have I Been Asked To Participate In This Study?}

You are being asked to take part in this trial/study because you are the caregiver of an infant born prematurely admitted to the neonatal intensive care unit at The Children's Hospital at OU Medical Center.

\section{Why Is This Study Being Done?}

The purpose of this study is to explore the effect of babywearing for caregivers being discharged from NICUs to their home environment. Babywearing is the practice of keeping a child close to your chest by using a soft baby carrier during daily activities.

\section{How Many People Will Take Part In The Study?}

Between 8 and 15 people will participate at this location.

\section{What Is Involved In The Study?}

For this research, you will receive education on using a baby carrier before discharge. We request that you babywear your infant for about three hours a day for two months following NICU discharge. Education will include fitting you with a carrier from that will remain yours after the study is completed. Initial education and fitting will take approximately one hour. The interviewing investigator is available for questions about using the baby carrier before and after your baby is discharged from the NICU. A follow up interview will be conducted in your home during a home visit that should take approximately 60 minutes. This interview will be recorded. After the interview is transcribed, the recording is destroyed.

A sample of possible interview questions are as follows:

How old are you?

How old is your baby?

How long did your child spend in the NICU?

What were the positives and negatives of your experiences with babywearing? 
What do you see as the benefits and difficulties of babywearing your baby?

How many hours per week have you worn your baby since we last spoke?

\section{How Long Will I Be In The Study?}

We think that you will be in the study for approximately two months.

There may be unanticipated circumstances under which your participation may be terminated by the investigator without regard to your consent. This may happen if you do not use your babywearing device during the study period, or the study is stopped by the research team. Any caregiver who is prescribed opioid medications or sedatives during the study will removed. Any caregiver or infant who is admitted to an acute care hospital during the study period will also be removed from the study.

You can stop participating in this study at any time. However, if you decide to stop participating in the study, we encourage you to talk to the researcher and your regular doctor first. There are no consequences for choosing to withdraw from the study.

\section{What Are The Risks of The Study?}

Potential risks of participating in an interview include the potential for stress and anxiety brought on by talking about your experience in the NICU prior to discharge. A majority of parents experience stress and anxiety related to a NICU admission and about 15-25\% experience situational PTSD. Talking about your experience has the potential to bring negative emotions to the forefront and cause stress and anxiety due to remembering this past traumatic experience. Phenomenology and interviewing in a qualitative manner can be used as therapeutic technique. Talking about your experience in the NICU, although potentially anxiety-producing, can assist you in establishing perspective and closure.

If you feel stress or anxiety during the interview, please verbalize this the investigator. The investigator will refer you to seek advice from your primary care provider. You will also be given a list of local support groups you may contact. The interview will be terminated at any time at your request.

\section{Are There Benefits to Taking Part in The Study?}

Babywearing is theorized to provide similar benefits as skin-to-skin care (kangaroo care) practiced in the NICU. Skin-to-skin care can reduce stress and anxiety for the caregiver and have multiple benefits for the infant such as decreased crying. There is little research on the benefits of babywearing.

If you agree to take part in this study, there may or may not be direct benefits to you and your infant. We hope that the information learned from this study will benefit other caregivers in the future who are interested in the benefits of babywearing.

The possible benefits of taking part in the study are the same as babywearing without being in the study. 


\section{What Other Options Are There?}

You have these options:

You may choose to receive information about babywearing but not participate in the study.

or

You may choose not to participate in the study or receive information.

Please talk to your regular doctor about these and other options.

\section{What about Confidentiality?}

Efforts will be made to keep your personal information confidential. You will not be identifiable by name or description in any reports or publications about this study. We cannot guarantee absolute confidentiality. Your personal information may be disclosed if required by law. You will be asked to sign a separate authorization form for use or sharing of your protected health information.

There are organizations outside the OUHSC that may inspect and/or copy your research records for quality assurance and data analysis. These organizations include the US Food \& Drug Administration, University of Central Oklahoma, The Children's Hospital at OU Medical Center and other regulatory agencies. The OUHSC Human Research Participant Program office, the OUHSC Institutional Review Board, and the OUHSC Office of Compliance may also inspect and/or copy your research records for these purposes.

\section{What Are the Costs?}

There is no cost to you if you participate in this study.

\section{Will I Be Paid For Participating in This Study?}

No financial incentive is involved in participating in this study, however, a baby carrier is provided for your use throughout the study and will remain yours after the study period is over.

\section{What if I am Injured or Become Ill While Participating in this Study?}

No funds have been set aside by The University of Oklahoma Health Sciences Center, The University of Central Oklahoma, or The Children's Hospital at OU Medical Center to compensate you in the event of injury.

A list of postpartum support groups are available through the investigators of this study. This list includes information about Oklahoma Family Network at www.oklahomafamilynetwork.org or by phone at 877- In addition, the Thrive Mama Collective holds a free, live support group for parents who have experienced antepartum stress or trauma, facilitated by a Master's prepared LCSW on the last Wednesday of every month. You can find more information by contacting them at info@,thrivemamacollective.com. 


\section{What Are My Rights As a Participant?}

Taking part in this study is voluntary. You may choose not to participate. Refusal to participate will involve no penalty or loss of benefits to which you are otherwise entitled.

If you agree to participate and then decide against it, you can withdraw for any reason and leave the study at any time. You may discontinue your participation at any time without penalty or loss of benefits to which you are otherwise entitled.

We will provide you with any significant new findings developed during the course of the research that may affect your health, welfare, or willingness to continue your participation in this study. We do not anticipate findings that may affect your health.

You have the right to access the medical information that has been collected about you as a part of this research study. However, you may not have access to this medical information until the entire research study has completely finished. You consent to this temporary restriction.

\section{Whom Do I Call If I have Questions or Problems?}

For questions or help with using the baby carrier, contact Robyn Miller at 405-

If you have questions, concerns, or complaints about the study or have a research-related injury, contact the Robyn Miller at 405 or Susan Bedwell at 405-

If you cannot reach the Investigator or wish to speak to someone other than the investigator, contact the OUHSC Director, Office of Human Research Participant Protection, at 405-

For questions about your rights as a research participant, contact the OUHSC Director, Office of Human Research Participant Protection at 405

\section{Signature:}

By signing this form, you are agreeing to participate in this research study under the conditions described. You have not given up any of your legal rights or released any individual or entity from liability for negligence. You have been given an opportunity to ask questions. You will be given a copy of this consent document.

I agree to participate in this study:

PARTICIPANT SIGNATURE (age $\geq 18$ )

(Or Legally Authorized Representative)

SIGNATURE OF PERSON

OBTAINING CONSENT

IRB Office Version Date: 09/21/2016
Printed Name Date

Printed Name $\quad$ Date 


\section{Appendix G}

\section{Study Contact Flyer}

\section{Babywearing Research Study}

Going home with your baby can be an exciting but stressful time. Using a baby carrier may help you take care of your baby and yourself.

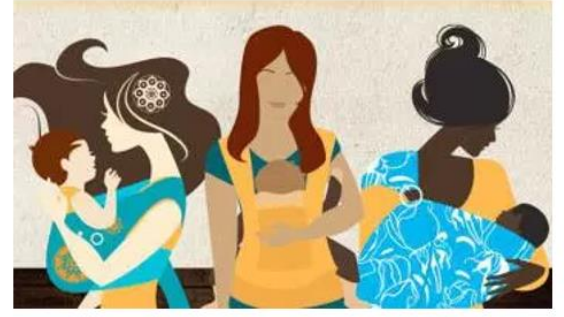

If you would like to be a part of this study, please call:

Robyn Miller at

Susan Bedwell at

(Link back to manuscript) 


\section{Appendix H}

\section{Caregiver Education}

\section{Babywearing after the NICU}

Going home with your baby after a NICU hospitalization can be an exciting but stressful time. You might feel anxious about not having the nurses and equipment you are used to, to help you care for your baby. Babywearing may help you take care of your baby while also helping you take care of yourself.

What is Babywearing?

Babywearing is the practice of keeping a child close to your chest by using a soft baby carrier during daily activities. A baby carrier should hold your baby to your chest in Kangaroo Position, as shown by this example:

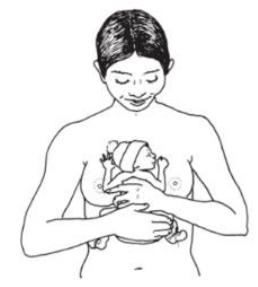

WHO guidelines for Kangaroo Care infant positioning. Retrieved from (http://apps.who.int/iris/bitstream/10665/42587/1/9241590351.pdf).

How Does Babywearing Help My Baby and Me?

Babywearing may be seen considered an extension of Kangaroo Care after you go home. Learning to use a baby carrier can take some time. You will have resources you can access to help you when you have questions. When your carrier is used correctly, you should not need to use your hands to hold your baby. You can use a baby carrier as a parenting tool that will allow you to take care of yourself while you are holding your baby. Babywearing may also help your baby feel secure and happy while they are getting used to being in a new environment. Many people find that babywearing helps their baby feel calm and they cry less.

\section{Learning to Babywear}

It's best to learn babywearing when your baby is calm, not hungry, or very tired. It's also a good idea for you to feel calm and not hungry before learning this new skill. You will have the opportunity to try on different styles of carriers before you go home. Everyone likes something different. It may take some time for you and your baby to get used to babywearing. Some babies love being worn right away, and some babies take their time before 
relaxing in a carrier. If your baby is not happy in the carrier, it's okay to try using it later. The goal is to wear your baby for at least three hours a day. Don't worry if it takes you a while to reach that goal. The point is that you and your baby are happy, comfortable, and each of you get your needs met.

\section{Making Babywearing the Best Experience!}

You may dress your baby in just a onesie, or other thin clothing. The warmth from your body will keep your baby warm. If you step outside, monitor your baby so they don't get too cold or hot. A baby's ears can be a good "thermometer". If your baby's ear tips are red and hot, your baby may be feeling to warm. If your baby's ear tips are cold or pale, your baby may be getting too cold. Do not expose your baby or yourself to extreme temperatures while babywearing.

If you wear a button up shirt, unbutton the top buttons so the baby is not laying on anything hard or uncomfortable. Do not wear shirts with zippers or other hard surfaces where the baby will be lying on your chest. Your baby is sensitive to smells so avoid wearing strong smelling substances. Do not smoke while babywearing.

Babies often fall asleep while being worn. This means your baby feels safe and calm. Make sure that your baby is fitted well in the carrier and that they do not slump over when they are asleep. You should be able to feel space between the baby's chin and chest. You should be able to see their face. You should also be able to hear and feel your baby breathing. Breathing should be silent, without gasping, snoring, or squeaking. If your baby is making these unusual sounds while sleeping, take the baby out of the carrier and contact your baby's provider. 


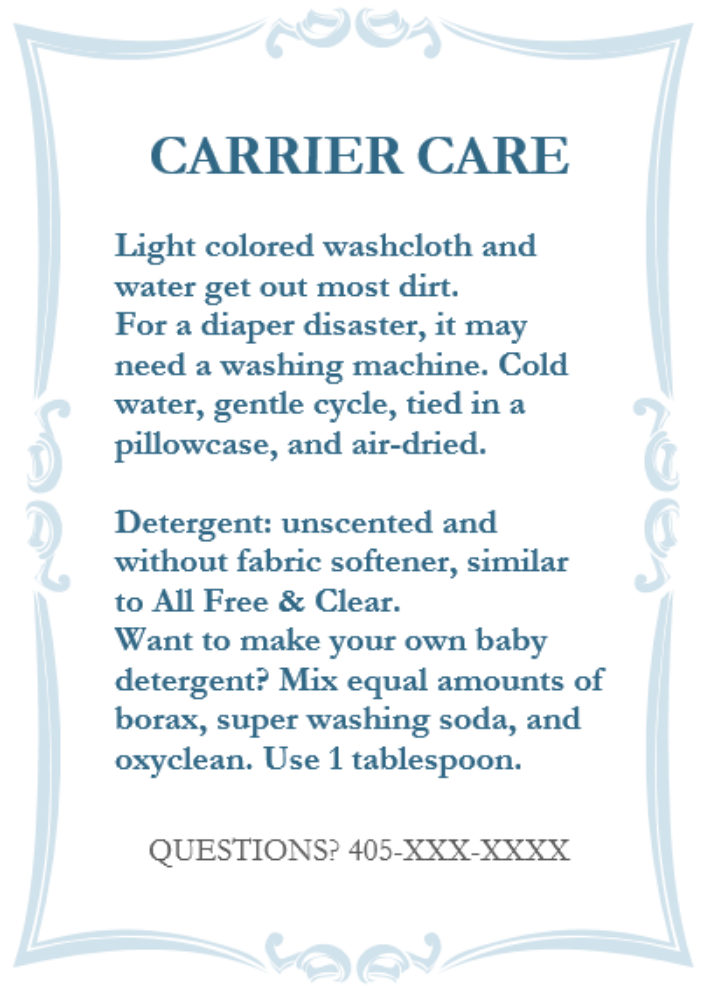

(Link back to manuscript) 


\section{Appendix I}

\section{Exemplars from Participant Answers to Interview Questions}

\section{Textural Descriptions}

Please talk about any positive and negative experiences with babywearing.

Participant 1 Positive - In the beginning she wanted to be in my arms constantly. If she was ever fussy as soon as I put her in there it was instant, she would go right to sleep. [The carrier] helped me to eat. I wish I had two more arms. Negative - It was hot. It was difficult to get used to putting it on. I could only put it on in front of a mirror. I'm not comfortable enough to use it in public. [Bottle] feeding interrupts the babywearing.

Participant 6 Positive - I really enjoyed it. It was helpful to be able to move around the house and not keep going back to check on her. I feel like I bonded with her more. I was able to keep her safer from germs in public.

Negative - A few times she would act irritated but I was either able to calm her down or just take her out and try again later.

Participant $7 \quad$ Positive - I loved it. All of it.

Negative - Sometimes it [the carrier] wouldn't stay tight and I had to readjust it. But it never felt like she was going to fall out, the way you do it.

Participant 10 Positive - I love having her strapped on and she seems to really love it. People are not as likely to touch her in public. It's flu season. People get closer to her and touch her when she's in her car seat but not when she's strapped on to me. 
Negative - I hadn't had any negative experiences with babywearing. Sometimes she doesn't like the act of me putting her in it but once she's in she's like, "Oh, this is fun."

Participant 12 Positive - It was great. It helps a lot when you're trying to do things around the house.

Negative - No.

Participant 13 Positive - It works. I have had back trouble and it takes the weight off my back.

Negative - Nothing negative.

Participant 14 Positive - It seemed a lot easier, like when you're trying to ride the bus you don't have to have a bulky stroller. [He] seems to really like it because it's up against your body and he can hear your heartbeat and it soothes him. He goes straight to sleep and stays asleep.

Negative - The hardest thing would be to put it on by yourself. You have to have another person to help make sure it's buckled and everything.

Participant 16 Positive - Very good. My baby and me, we mop, sweep, make food. Negative - No, it's fine.

What was it like being (baby's name) parent before and after learning about babywearing?

Participant 1 I was scared to carry her at first because of the [C-section] incision. It was a lot more convenient once I could wear her. I had my hands free.

Participant 6 Compared to my other kids, I've bonded with her better. It's different this time because I'm a single parent. I can tell you she hasn't gotten sick! 
She's stayed really healthy. My other kids got sick right away with an ear infection.

Participant 7 I felt closer to her. She loves to be held like that.

Participant 10 I planned to wear her back when I was pregnant because I had to take her to class.

Participant 12 It was great.

Participant 13 Being a first time dad is kind of weird, but it's actually kind of neat. [The carrier] is very easy to clean and easy to put up.

Participant 14 It's been a good experience. This whole experience with [son] has been a learning experience.

Participant 16 It helps take care of the baby. My baby no crying, is safe with me.

Has the rhythm of your activities of daily living changed before and after learning about babywearing? How?

Participant 1 I was definitely able to do more laundry. She has a tongue tie that we're getting revised [tomorrow]. If I'm able to nurse her [in the carrier] then that'll be a game changer.

Participant 6 It was really hard leaving her, not having her with me. Babywearing did enable me to do more than I would have. I was able to put my makeup on and do up my hair. Which made me feel better about the day. Even if I didn't go anywhere!

Participant 7 I thought I was going to have to transfer her to each room but now she just...comes with me! 
Participant 10 I am actually more likely to clean if I am babywearing. She likes for me to move around. I vacuumed last night for two hours trying to get her to go to sleep, so...

Participant 12 No, not really because I still do them, I'll be washing dishes and stuff like that. It doesn't change nothing. It helps me because he's right there on my chest.

Participant 13 Everything is pretty much still the same. If we need to go somewhere we just strap him up and off we go.

Participant 14 If I had the carrier on I can still do housework and still do dishes. When he's really fussy and he doesn't want you to lay him down for nothing. He won't stay asleep for long [out of the carrier].

Participant 16 I use it every day to mop, sweep, make food, everything.

How many hours a day did you babywear? Did other parents or caregivers also wear (baby's name)?

Participant $1 \quad 2-4$ hours. Never all at the same time, usually one hour at a time. Sometimes two hours at a time. One time three hours flew by! No one else wore [baby]. Everybody thought it was too complicating.

Participant $6 \quad 2-4$ hours. I left it in my diaper bag when I left her with my cousin. They didn't have the instructions but they had tried to put it on. They thought it was pretty neat.

Participant 7 It depended on the day. Weekends got more. She did come with me to work one time, and I wore her the whole time I was there. 
No [other people wore her].

Participant 10 On average an hour a day. Some days I don't have her in it hardly at all.

Like one week I thought I had the flu and I didn't want to get her sick so....it was a weird week for her. I would breastfeed her and put her down and she'd be like, “Why aren't you holding me?” I'd be like, “I'm sorry! I just don’t want to make you sick!”

Participant 12 I don't remember (laughs). It was once in a while at a time.

Participant $13 \quad$ 2-4 hours a day.

Participant 14 3-6 hours a day. It just depends on what I'm doing. It depends on how many times I have to clean the house.

Participant $16 \quad$ 2-3 hours, sometimes more hours.

How did you perceive the requested amount of time per day spent babywearing? (3 hours) Did it seem long or short to you?

Participant 1 It seemed long but once I started, it doesn't [seem long]. Once it was on, time flew by.

Participant 6 Having it out in the open, on the couch, it reminded me to use it. But once I was holding her, time didn't really seem to be a factor.

Participant $7 \quad$ Short.

Participant 10 It just depends. I don't think I meet the goal, I know I don't meet the goal, but some days it's no big deal to have her in it for three hours. And then some days I can't seem to find time to have her in it at all. I wear her when I take her to work. 
Participant 12 It was a short time because I was doing everything I needed to do. It was short.

Participant 13 About a medium amount of time. It didn't seem long at all.

Participant $14 \quad$ It seemed short.

Participant 16 For me, it's fine because in three hours I clean my freezer, my stove, everything.

\section{Structural Descriptions}

What is it like to be a babywearer?

Participant 1 I like it. I think it's convenient. It make me feel more secure to [say no to] baby hogs. Especially in the beginning I want her all the time.

Participant 6 It makes me feel like a good mom. I got compliments on it out in public. A man said, "Does that look girlish? Because I'd really like to have one when I have a baby."

Participant 7 I think it's more accomplishing. I don't have to worry.

Participant 10 It is convenient. I don't feel as paranoid that somebody is going to try to kidnap her? Which is illogical but if she's strapped to me then she can't get kidnapped (laughs). Somebody would have to go to a lot of effort to kidnap her if she's strapped to me.

Participant 12 It was great! It helped.

Participant $13 \quad$ Normal. I don't see why people would feel embarrassed about wearing it. I've actually had two people ask me what it was and I told them, it's just something that I hold my son in. Instead of having to roll him around, I can carry him. 
Participant 14 It's a lot easier. Easier than a stroller.

Participant 16 [Easier] for the breastfeeding. [Feeds him while in the carrier]

What do you see as the benefits and difficulties of babywearing (baby's name)?

Participant 1 It just feels SO good, it's just such a feeling of love, like you and your baby are hugging.

Participant 6 I didn't really have any difficulties. I would recommend it to anyone.

Participant 7 [Difficulty] Getting the thing on sometimes! [Benefit] Well, I don't have to lug that car seat around when I go into the store.

Participant $10 \quad$ Well, it's convenient. I don't like to carry around her carrier [car seat] because it's heavy and I'm lazy? Having her strapped to me is easier and she seems to stay calmer. If I do take her to class I put her in the carrier and she stays calm until she gets hungry. And I still have nothing negative to say about it so....(laugh).

Participant $12 \quad$ No, easier!

Participant 13 I don't see any difficulties. It's easy to place, easy to wash off, easy to put up. It's real easy and simple.

Participant 14 I don't think there has been a difficult thing. Feeding might be the only difficult part. I had to take him out because I couldn't figure out how to hold the bottle while walking.

Participant 16 Easy? For me, cooking. Difficult was mop. [because she has to bend over] 
Would you recommend babywearing to your friends or your children?

Participant $1 \quad$ Yes, I would.

Participant 6 Yes, I would.

Participant $7 \quad$ Yes, to everybody. [talking to baby] It's so much easier!

Participant $10 \quad$ Yeah, absolutely.

Participant $12 \quad$ Ya?

Participant 13 Oh yeah, most definitely.

Participant 14 Yeah, in fact my son has even borrowed it a time or two [for his baby].

Participant $16 \quad$ Yes. Definitely Yes.

Tell me some words you think describe (baby's name).

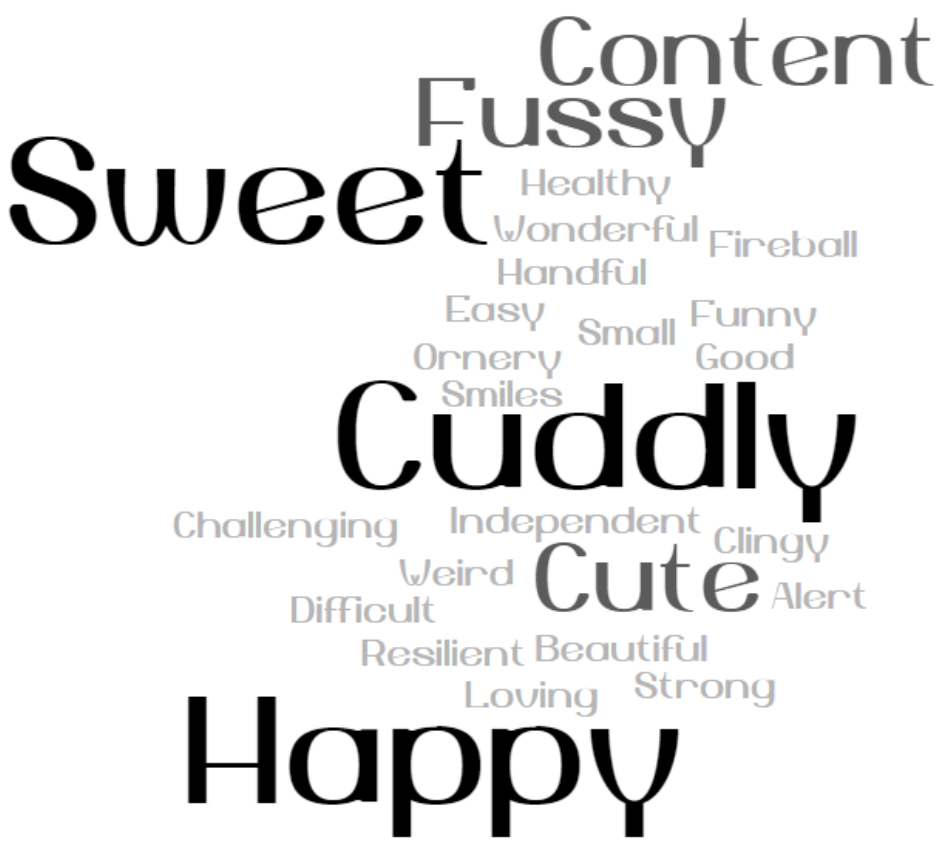

Figure 3: Word cloud. Larger and darker font indicate words used more often. 
Participant 1 She does things her own way. She impressed me. She's a really good baby.

Participant 14 One minute he's fussy all day long and he could be this little cuddle bug. In the hospital he tries to figure out which nurse he can win her heart.

Participant 16 Happy because every time he is here with me! (laughs)

Is there anything else you would like to share about your experiences babywearing (baby's name)?

Participant 1 If you hadn't come in the room that day, I probably wouldn't have baby, babyworn, babywearing, wouldn't have done that for a while.

Participant 6 Other than just recommending it to anyone and everyone.

Participant 7 I get to stay closer to her, and I don't have to worry about her.

Participant 13 Anyone who says they don't want to wear one, you don't know what you're missing!

Participant $14 \quad$ It's a different experience and you get to bond with them more.

Participant 16 It's more time with my baby. Sometimes he sleep here.

Is there anything else you would like to add or share?

Participant $1 \quad$ I wish I could have tried all the carriers!

Participant $7 \quad$ I'm just happy I got to do it. Because I probably wouldn't have thought of babywearing if I wouldn't have done the study.

Participant $10 \quad$ I like babywearing.

Participant 16 Me? I like it. For me, I like. 


\section{Appendix J}

\section{Coding of Study Data}

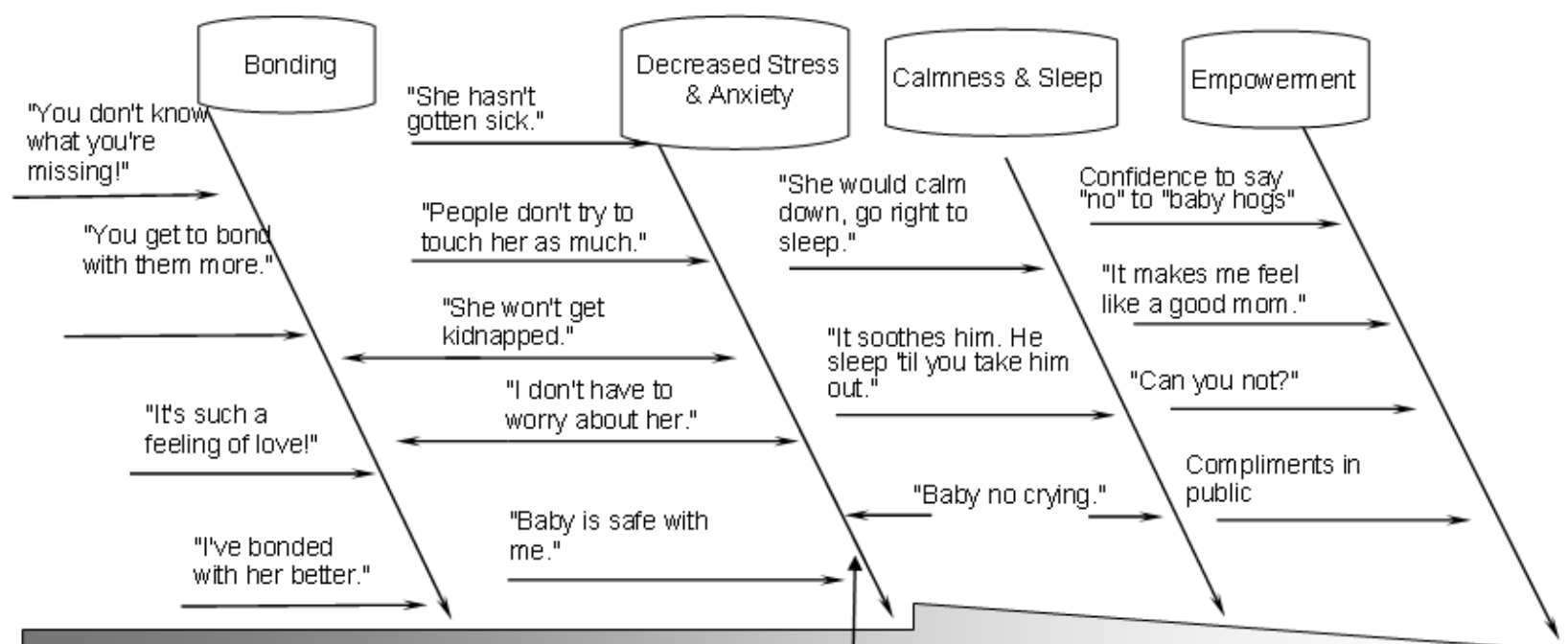

\section{"What is the Experience of Babywearing NICU Graduates?"}

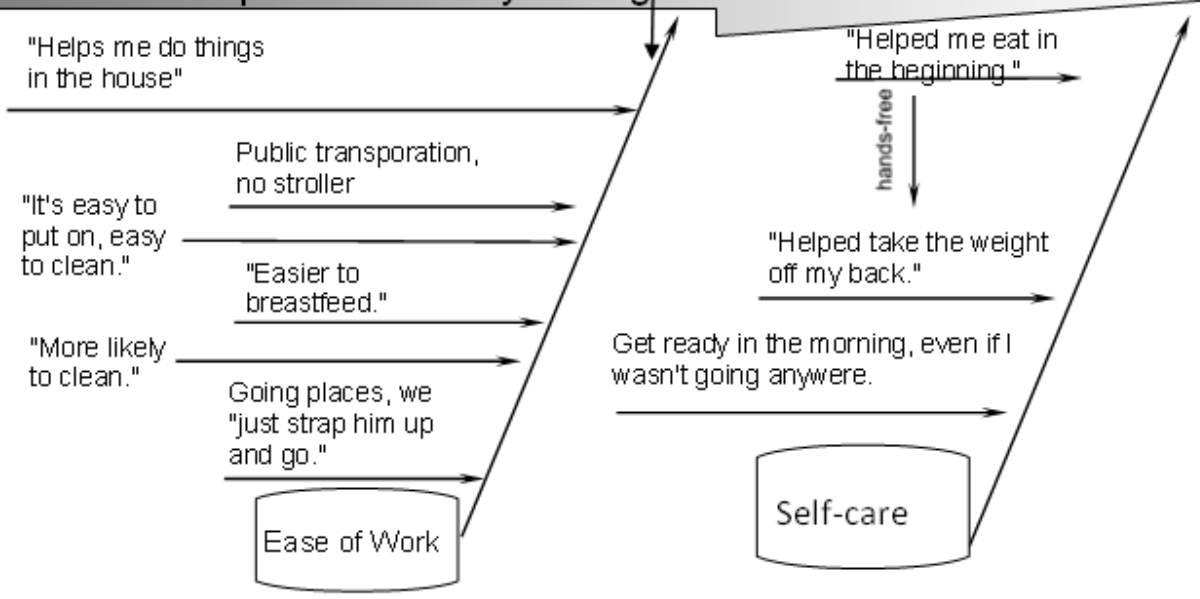

(Link back to manuscript) 